\title{
A Meta-Analytic Review of Social Identification and Health in Organizational Contexts
}

Niklas K. Steffens ${ }^{1, *}$, S. Alexander Haslam ${ }^{1}$, Sebastian C. Schuh², Jolanda Jetten ${ }^{1}$,

$$
\text { Rolf van Dick }{ }^{3,4}
$$

${ }^{1}$ School of Psychology, The University of Queensland, Australia

${ }^{2}$ Department of Organizational Behavior, China Europe International Business School, China

${ }^{3}$ Department of Psychology, Goethe University Frankfurt, Germany

${ }^{4}$ Work Research Institute (AFI), Oslo, Norway

* Correspondence concerning this article should be addressed to: Niklas K. Steffens, School of Psychology, The University of Queensland, Brisbane, St Lucia QLD 4072, Australia. E-mail: N.Steffens@uq.edu.au; Fax: +61 (0)7 3365 4466; Tel.: +61 (0)7 33469555.

To Appear in: Personality and Social Psychology Review

\section{Author Note}

This work was supported by two grants from the Australian Research Council awarded to SAH (FL1 10100199) and JJ (FT110100238). We thank the researchers whose work is included in this analysis for their time and effort in helping us to gather all relevant data. We also thank Miriam Yates, Hannibal Thai, and Nerisa Dozo for help with data analysis and Tom Postmes for helpful comments on an earlier version of this manuscript. 


\begin{abstract}
We provide a meta-analytical review examining two decades of work on the relationship between individuals' social identifications and health in organizations (102 effect sizes, $k=58, N=19,799)$. Results reveal a mean-weighted positive association between organizational identification and health $(r=.21, T=.14)$. Analysis identified a positive relationship for both workgroup $(r=.21)$ and organizational identification $(r=.21)$, and in studies using longitudinal/experimental $(r=.13)$ and cross-sectional designs ( $r=.22)$. The relationship is stronger (a) for indicators of the presence of well-being ( $r=.27)$ than absence of stress $(r=.18)$, (b) for psychological $(r=.23)$ than physical health $(r=.16)$, (c) to the extent that identification is shared among group members, and (d) as the proportion of female participants in a sample decreases. Overall, results indicate that social identifications in organizations are positively associated with health but that there is also substantial variation in effect size strength. We discuss implications for theory and practice and outline a roadmap for future research.
\end{abstract}

Keywords: social identity; identification; health; well-being; meta-analysis 
The topics of stress and well-being provide a major focus for research in social, organizational, and health psychology (e.g., Anisman, 2014; Lundberg \& Cooper, 2011). This is for the simple reason that stress, fatigue, and burnout are costly not only for the individual organizational members who suffer and experience reduced functioning, but also for the organizations whose effectiveness is compromised by staff underperformance, absence, and turnover, and for society as a whole that incurs the costs of remediation and treatment. As a corollary, efforts to promote well-being can have significant benefits at individual, organizational, and societal levels (e.g., Helliwell, Layard, \& Sachs, 2013).

It is noteworthy that, in addition to sparking scholarly interest, health in the workplace has also become an important issue in society at large as part of efforts to cultivate engaged workplaces and healthy populations. In this regard, societies across the globe take a keen interest in issues of health not only as a result of rising health expenditure but also because health metrics are increasingly seen to be important indicators of national prosperity (e.g., as seen in national initiatives such as the UK's Happiness Index and the EU's Quality of Life Survey and in global initiatives such as the Social Progress Index and the World Happiness Report; Helliwell et al., 2013). Moreover, health is an important topic for organizations that care about the well-being of individuals for either intrinsic or extrinsic reasons (e.g., because they care about creating value and attracting and retaining talent or because this is associated with enhanced productivity and profitability). Indeed, speaking to the wider significance of health for organizations, metaanalytic evidence suggests that individuals' health often precedes their capacity to perform (Lyubomirsky, King, \& Diener, 2005).

With a view to understanding issues of stress and well-being in organizations, an emerging body of research suggests that one factor that has important consequences for psychological health and well-being in the workplace is people's social group memberships 
(Jetten, Haslam, \& Haslam, 2012). More particularly, there is evidence that a person's internalization of a relevant group in the work context (a workgroup, an organization) as part of their self-concept has important consequences for stress and burnout (Horton, McClelland, \& Griffin, 2014; Wegge, van Dick, Fisher, Wecking, \& Moltzen, 2006). Here the group furnishes them with a sense of social identity (as "we" and "us" rather than just "I" and "me"; Ashforth \& Mael, 1989; Tajfel \& Turner, 1979) and this has been shown to have profound implications for the experience of stress, social support, and resilience more generally (e.g., Drury, 2012; Muldoon \& Downes, 2007).

Nevertheless, the precise consequences of workplace social identifications for stress and health are unclear. On the one hand, research suggests that individuals' increased social identification with a workgroup and/or an organization is positively related to their health, because, among other things, this provides a basis for increased support, control, and resilience (Greenaway et al., 2015; Haslam, O’Brien, Jetten, Vormedal, \& Penna, 2005). On the other hand, identification may compromise health because, among other things, increased identification is associated with working long hours (Ng \& Feldman, 2008) and this is associated with reduced health (Golden \& Wiens-Tuers, 2006).

As well as establishing whether increased identification enhances or compromises health, our core aim in the present research is to estimate the nature and precise strength of this relationship (i.e., with reference to effect-size and confidence intervals). This is important because such analysis provides a basis (a) for future research to gauge the importance of social identification for workplace health, (b) for integrating the insights of the present analysis into such future research, and, ultimately, (c) for building a more accurate and robust quantitative science (Cumming, 2014). With this goal in mind, we use a range of advanced methods to estimate and correct for measurement and publication bias so as to gain a more precise estimate 
of the true effect size of this relationship.

In addition to estimating the global summary effect size of the identification-health relationship, we seek to shed light on theoretically and practically important moderators of the relationship by examining the extent to which its strength is affected by (a) the focus of identification (workgroup vs. organization), (b) health valence (positive vs. negative), (c) the nature of the health index (psychological vs. physical), and (d) the sharedness of identification (shared vs. non-shared). Furthermore, we perform exploratory analyses of several additional potential moderators (including the scale used to assess social identification, study methodology, gender and age of participants, status of profession, and the Inglehart-Welzel cross-cultural dimensions). Finally, we use the findings of the analysis as a basis for developing an agenda for future theory, research, and practice with a view to helping the field move forward.

\section{Social Identification and Health in Organizations}

A growing body of evidence points to the important role of social factors in people's experience of health (Cacioppo, Hawkley, \& Bernstein, 2003; Cohen, 2004; Diener \& Biswas-

Diener, 2008; Helliwell \& Putnam, 2004; Holt-Lunstad, Smith, \& Layton, 2010). In recent years, one significant strand of this work has been informed by social identity theorizing. This starts from the assertion that people are able to think, feel, and act not just as individuals (i.e., in terms of a personal identity as "I") but also as group members (in terms of a social identity as "we"; for reviews, see Ellemers, 2012; Postmes \& Branscombe, 2010; Reicher, Spears, \& Haslam, 2010; Hogg \& Abrams, 1988; Turner, Hogg, Oakes, Reicher, \& Wetherell, 1987; Turner, Oakes, Haslam, \& McGarty, 1994). The approach argues that when people categorize themselves as members of a group (e.g., "us members of Organization X"), this makes them more likely to see the world from the perspective of fellow ingroup members, more open to influence from ingroup members, and more likely to trust and cooperate with ingroup (rather than outgroup) members 
(Turner, 1991). This in turn is the basis for a range of distinctive forms of organizational behavior — including motivation, communication, collaboration, and leadership (Ashforth \& Mael, 1989;

Blader \& Tyler, 2009; Ellemers, de Gilder, \& Haslam, 2004; Haslam, 2004; Hogg \& Terry, 2001; Tyler \& Blader, 2003).

One of the key applications of the social identity approach to the domain of health has argued that self-categorization in terms of a relevant group membership has significant implications for the experience of stress and well-being (Branscombe, Schmitt, \& Harvey, 1999; Gleibs et al., 2011; Sani, Herrera, Wakefield, Boroch, \& Gulyas, 2012; for recent reviews see Haslam, Jetten, Postmes, \& Haslam, 2009; Jetten et al., 2012). This is for a number of reasons, many of which speak to insights from the transactional model of stress (Lazarus \& Folkman, 1984). First, this approach led researchers to predict that to the extent that people self-categorize as group members, their primary appraisal of stressors will be affected by the circumstances and views of their ingroup - a point confirmed in research which has shown that appraisal is determined both by the significance of a stressor for a particular social identity (Levine \& Reicher, 1996) and by feedback about stressors from ingroup (but not outgroup) members (Gallagher, Meaney, \& Muldoon, 2014). Second, self-categorization in terms of a given group membership also serves as a basis for active coping processes in the form of secondary appraisal. In particular, this is because when they are acting in terms of a shared group membership, people should be more likely both to receive support from fellow ingroup members and to interpret that support in the spirit in which it is intended (Levine, Cassidy, Brazier, \& Reicher, 2002; Levine, Prosser, Evans, \& Reicher, 2005).

As an instantiation of these fundamental points, research has found that people's experience of stress and well-being in the workplace is significantly structured by the nature of their social identifications — that is, their strength of identification with a given group — as 
members of either a workgroup or the organization as a whole (for a recent review, see van Dick \& Haslam, 2012). Illustrative evidence emerges from a field study conducted by van Dick and Wagner (2002) which observed that high levels of organizational identification were related not only to organizational outcomes such as job satisfaction and motivation but also to reduced experience of strain. Similarly, a study by Bizumic, Reynolds, Turner, Bromhead, and Subasic (2009) found that a fairer and more inclusive school climate was associated with reduced stress among teachers partly because it served to enhance teachers' identification with the school.

It is the case, however, that there is a range of factors associated with increased social identification may have positive and negative effects on health. Therefore, we can anticipate that the link between social identification and health in organizations could take one of several plausible forms: ranging from an overall positive association (an invigoration perspective), to an overall negative association (an exhaustion perspective), or an overall absence of an association if these effects were equally strong (a neutralization perspective). Key theoretical backgrounds and literatures that lend support for these alternative hypotheses concerning the identification-health relationship are summarized in Table 1 . As can be seen from this table, there are at least six established literatures that support an overall positive association. Briefly, these suggest that social identifications in organizations will be associated with better health because identification provides people with (a) a sense of belonging (Baumeister \& Leary, 1995; Ryan \& Deci, 2000), (b) a sense of meaning and purpose (van Dick \& Wagner, 2002; Wegge et al., 2006), (c) a sense of control and agency (Greenaway et al., 2015; Reicher \& Haslam, 2006), and (d) a source for self-affirmation and a positive attribution style (Cruwys, South, Greenaway, \& Haslam, 2015; Sherman, Kinias, Major, Kim, \& Prenovost, 2007). Furthermore, literatures indicate that social identification is the basis for people's experience of (e) social support (Levine et al., 2002; Haslam et al. 2005) as well as (f) collective self-efficacy (Shamir \& Kark, 2004; van Zomeren, 
Leach, \& Spears, 2012) - experiences that are positively associated with health in the workplace (Avanzi, Schuh, Fraccaroli, \& van Dick, 2015).

At the same time, there are at least four important literatures which suggest that social identification is associated with factors that have negative effects on people's health. These imply that increased social identification will lead to a downward health spiral because increased identification is associated with (a) excessive involvement as well as heightened demands and pressure to perform (Herrbach, 2006; Mühlhaus \& Bouwmeester, 2016) and (b) working long hours (Escartiín, Ullrich, Zapf, Schlüter, \& van Dick, 2013; Ng \& Feldman, 2008), which reduce people's capacity to engage with other meaningful groups outside work (Golden \& Wiens-Tuers, 2006; Pratt et al., 2000). In addition, lines of research on (c) dirty work and stigma (Ashforth \& Kreiner, 1999; Branscombe et al., 1999) and (d) group norms and identity motivation (Oyserman \& Fryberg, \& Yoder, 2007; Perkins \& Wechsler, 1996; Tarrant, Hagger, \& Farrow, 2012) indicate that increased identification can lead to increased stress and diminished health to the extent that groups are stigmatized and endorse norms that prescribe health-damaging habits and behaviors.

In the present meta-analysis, we review the large body of evidence that speaks to these issues with a view to establishing whether increases in either workgroup identification or organizational identification are generally unrelated to health or associated with the experience of improved or impoverished health. In addition to estimating the global magnitude of the summary effect of the relationship between social identifications and health in organizations, we also examine whether the strength of this relationship varies as a function of several key moderating factors. Specifically, we examine moderating factors that have received relatively little attention in previous research but that are theoretically important in determining when the positive and negative effects of identification are stronger or weaker (or absent). In what follows, we will 
briefly introduce these factors. Key literatures that support alternative hypotheses for these a priori moderators of the positive effects associated with social identification are summarized in Table 2.

\section{Health as a Function of Workgroup versus Organizational Identification}

As outlined earlier, there are reasons to believe that both workgroup and organizational identification will be positively related to health. However, there are several reasons why health should be differentially associated with one entity relative to the other. First, one might expect the identification-health relationship to be stronger for workgroups than for organizations due to the greater salience of workgroups and their more proximal nature (Ashforth \& Johnson, 2001; Barker \& Thompson, 1994; van Knippenberg \& van Schie, 2000). Second, one might also expect stronger effects for workgroups because we know from literatures on group socialization and cohesion that people are more familiar with members of smaller groups and experience smaller (work)groups as more cohesive (Anderson \& Thomson, 1996; Carron \& Spink, 1995; Moreland \& Levine, 2001).

While the previous two arguments suggest that the positive effects of health will be stronger for workgroup than for organizational identification, other literatures and models suggest the opposite. First, as workplaces evolve, people are more likely to experience change at the level of the workgroup (e.g., in terms of roles, tasks, membership) than at the more abstract level of the entire organization. Building on research on continuity (Sani, 2008; Sani, Bowe, \& Herrera, 2008) and enduringness of self (Albert \& Whetten, 1985), one might therefore expect that people are more likely to derive positive effects associated with identification with an organization because this is more likely to provide them with a sense of stability and continuity. Second, previous research indicates that public regard is an integral aspect of collective self-esteem (Dutton, Dukerich, \& Harquail, 1994; Luhtanen \& Crocker, 1992) and accordingly one might, 
expect that positive effects will be stronger for organizational (rather than workgroup)

identification because more encompassing organizations are likely to be recognized and respected by a wider circle of people in society.

\section{Identification and the Presence of Well-Being versus the Absence of Stress}

Following in part from the rise of positive psychology (Diener, 2000; Seligman \& Csikszentmihalyi, 2000), researchers have pointed to the important distinction between negative aspects of health such as burnout (Lee, \& Ashforth, 1996; Maslach, \& Jackson, 1981; Maslach, Schaufeli, \& Leiter, 2001) or depression (Cruwys, Haslam, Dingle, Haslam, \& Jetten, 2014) and other more positive aspects such as engagement and salutogenesis (Bakker, Schaufeli, Leiter, \& Taris, 2008; Graeser, 2011; Lindström \& Eriksson, 2006). In these terms, health is reflected in either the absence of negative indicators of health (e.g., the absence of stress such as burnout or strain) or the presence of positive indicators of health (e.g., the presence of well-being such as work engagement or general health). This distinction rests on the observation that the absence of illness is not the same as the presence of well-being and, indeed, that these are qualitatively distinct states. In short, although these different experiences may often go hand in hand, this is not inevitably the case. Just because an individual is experiencing stress this does not necessarily mean that they are unhappy and unfulfilled, and just because an individual feels happy and fulfilled this does not necessarily mean that they are free of stress.

Theoretical insights from the social identity approach suggest that organizational identification will be related both to reduced stress and increased well-being. Indeed, this is what previous studies have tended to report (e.g., Horton et al., 2014). Nevertheless, the literature on psychological accounts of positive human health (Ryff \& Singer, 1998; Thoits, 1994) suggests that people's health is influenced by their agency (and not passive surrender to stressors) and a consequence of individuals' sense of having meaningful and purposeful lives. Furthermore, 
phenomenological analysis indicates that high social identification is generally construed to be a basis for experiencing positive outcomes (e.g., support, belonging, control, agency; Haslam et al., 2009) rather than to be a basis for avoiding negative outcomes (Cruwys et al., 2014). This literature lends support for the notion that stronger positive effects will be found when health is conceptualized in terms of the presence of well-being rather than the absence of stress. At the same time, research on the stress-buffering effects of groups indicates that the resources that groups provide are especially helpful in the context of experiencing stressful events (Branscombe et al., 1999; Crabtree, Haslam, Postmes, \& Haslam, 2010; see also Thoits, 1986), suggesting that the positive effects associated with identification will be particularly pronounced in helping people to cope with stressful events and thereby in reducing their negative experience of strain.

\section{Identification and Physical versus Psychological Health}

Another common and important distinction that is made in the literature is between psychological health (Berkman, 2001; Scheier \& Carver, 1992; Taylor \& Brown, 1988) and physical health (Cohen, Doyle, Skoner, Rabin, \& Gwaltney, 1997; Uchino, 2009; Uchino, Cacioppo, \& Kiecolt-Glaser, 1996). Psychological indicators typically comprise felt and experienced states that relate to health and well-being (e.g., fatigue, burnout, stress, comfort, well-being) while physical indicators comprise experiences or biological markers of physical or physiological functioning (e.g., frequency of physical symptoms, physiological functioning, pain, cortisol levels). As in the case of positive and negative indicators of health, although psychological and physical health are likely to be strongly inter-related in many contexts, they capture distinct aspects of health and, accordingly, can in fact diverge from each other (e.g., so that reduced physical functioning does not necessarily accompany reduced life satisfaction; see Howell et al., 2014).

Social identity theorizing suggests that social identification in the workplace is likely to 
be associated with health as captured not only by psychological markers (e.g., Bizumic et al., 2009; Harris \& Cameron, 2005) but also physical ones (e.g., Häusser, Kattenstroth, van Dick, \& Mojzisch, 2012; Wegge et al., 2006). Nevertheless, there are at least two important reasons why social identification might be associated more strongly with psychological than physical health. First, in line with the literature on attitude-behavior compatibility in levels-of-analysis (Fishbein \& Aijzen, 1974; see also Riketta \& van Dick, 2005), as a psychological construct (grounded in, and experienced through, cognitions, emotions and behaviors; Ashforth, Harrison, \& Corley, 2008; Ellemers, Kortekaas, \& Ouwerkerk, 1999; Leach et al., 2008; Turner, 1982), social identification is likely to be linked particularly strongly to experiences at this psychological level. Second, a body of work indicates that individuals often connect socially with others by engaging in risky behavior and by jeopardizing their physical health (Howell et al., 2014; Hopkins \& Reicher, 2016), suggesting that increases in identification will be related more strongly to increases in psychological health than increases in physical health.

\section{Shared Social Identification}

Research informed by the social identity approach asserts that social identity is the "cognitive mechanism that makes group behavior possible" but that it is nevertheless an aspect of the self-concept that is represented and realized in the mind of the individual (Turner, 1982, p. 21). Along these lines, research conceptualizes and captures social identification at the level of the individual, as reflected in standard identification measures that assess the extent to which an individual identifies with, or self-categorizes in terms of, a group as an individual group member (e.g., assayed via items such as "I identify with [this group]"; I see myself as a member of [this group]"; e.g., Abrams, Ando, \& Hinkle, 1998; Brown, Condor, Mathews, Wade, \& Williams, 1986; Cameron, 2004; Doosje, Ellemers, \& Spears, 1995; Ellemers et al., 1999; Jackson, 2002; Leach et al., 2008; Mael \& Ashforth, 1992; Phinney, 1992; Postmes, Haslam, \& Jans, 2013; 
Roccas, Sagiv, Schwartz, Halevy, \& Eidelson, 2008; Sellers, Smith, Shelton, Rowley, \& Chavous, 1998; van Dick, Wagner, Stellmacher, \& Christ, 2004). Significantly, identification as assessed by identification scales can be more or less shared among group members. This degree of sharedness in social identification may be important to consider for theoretical reasons in allowing for a fuller understanding of what social identification is and how it plays out in the psychology and behavior of group members (see also Haslam, 1997; Tajfel, 1981).

Here it is important to note that the issue of sharing attributes more generally has previously been proposed to be an important feature of group attitudes and behavior. For instance, in the multicomponent model of group identification, Leach and colleagues (2008) identify individual self-stereotyping (sharing attributes with other members) and perceived homogeneity (being similar to other group members) as distinct components of social identification. There are some interesting parallels between perceived homogeneity and individual self-stereotyping on the one hand and sharedness in identification on the other. In particular, perceived homogeneity and individual self-stereotyping are similar to sharedness in identification in that both refer to shared attributes among group members. At the same time, they also differ from each other in two ways: (a) the former refer at an abstract level to any shared attributes that are seen to define a group (which could relate to identification but need not) while the latter refers specifically to identification as the attribute that is shared, and (b) the former refer to perceptions of shared attributes, while the latter refers to actual sharedness in identification.

Sharedness in identification is likely to be important for group members' psychology because an individual whose level of social identification is similar to that of fellow group members is likely to have a different orientation to, and experience of, the group than an individual whose level of social identification is not shared in this way. This is for two reasons. First, because shared social identity is likely to provide a particularly strong basis for trust and 
mutual influence (e.g., Haslam, Reicher, \& Platow, 2011; Tanis \& Postmes, 2005; Steffens et al., 2014; Turner \& Reynolds, 2001). Second, because research indicates that group entitativity is important in itself (e.g., Campbell, 1958; Hamilton \& Sherman, 1996; Lickel et al., 2000), and in newly forming groups, entitativity has been shown to strengthen both people's perceptions of groups and their feeling of belongingness in them (Jans, Postmes, \& van der Zee, 2011). Accordingly, and as shown by Jans, Leach, Garcia, and Postmes (2015), while it is useful and meaningful to treat identification as an individual difference measure on its own, it is likely that this fails to capture the full range of identity-informed psychology and behavior. Specifically, Jans and colleagues (2015) found that identification at the collective level had an additional impact (above and beyond an individual's own level of identification) on a group member's subsequent development of identification with the group. Surprisingly, prior social identity research has not examined this aspect in relation to health and our meta-analysis provides a unique opportunity to shed light on the effects of sharedness on the identification-health relationship.

One reason why the positive identification-health relationship is likely to become more pronounced as social identity is more shared among group members relates to the idea that shared social identity is the basis for solidarity (Drury, Cocking, \& Reicher, 2009; Reicher, Cassidy, Wolpert, Hopkins, \& Levine, 2006) that may promote their experience of well-being. Furthermore, the positive effects are likely to become amplified when identification is shared because shared social identity is likely to lead to more cohesive groups that in turn are likely to amplify the positive health benefits associated with identification (Blanchard, Amiot, Perreault, Vallerand, \& Provencher, 2009; Griffith, 2002). At the same time, however, the literature on the benefits of individual distinctiveness (Cantor, Kemmelmeier, Basten, \& Prentice, 2002; Hornsey \& Jetten, 2004; Markus \& Kitiyama, 1994; Sheldon \& Bettencourt, 2002) might lead one to 
expect that sharedness in identification is likely to weaken the positive effects associated with identification due to greater obstacles to harness the benefits of individual distinctiveness. Again, then, this is an important theoretical and empirical question upon which our analysis can shed powerful light.

\section{The Present Research}

In the present meta-analysis we aim to examine the above hypotheses by taking stock of the extensive body of research that pertains to the relationship between social identification and health in organizations in order to provide a more robust and precise estimation of the size of this relationship (Cumming, 2014). In order to assess the extent to which the magnitude of the effect size estimates based on the present set of studies are influenced by various biases that hinder the advancement of science (e.g., selective publishing, small study effects, $p$-hacking) and to yield estimates of the true unbiased effect size, we also employ a number of state-of-the-art techniques to estimate and correct for measurement and publication bias. In addition, we examine the capacity for a variety of novel and theoretically important variables — specifically, focus of social identification (workgroup vs. organization), health valence (negative vs. positive indicators), nature of health index (physical vs. psychological health), and sharedness in identification - to moderate the strength of this relationship. Moreover, for exploratory purposes, we also examine several additional variables (scale of identification, study methodology, gender an age of participants, status of profession, and the Inglehart-Welzel crosscultural dimensions) as potential moderators of the identification-health relationship. In pursuing these aims, we follow the meta-analysis reporting standards specified by the American Psychological Association (APA Publications and Communications Board Working Group on Journal Article Reporting Standards, 2008) concerning both our meta-analytic procedure and the reporting of relevant information. 


\section{Method}

\section{Study Search}

Two independent coders searched for studies in the major databases Web of Science, PsychINFO, PsyArticles, and MEDline by using the keywords "social identity/social identification/team identification/workgroup identification/organizational identification and health/stress/burnout/exhaustion/fatigue/sickness/physical symptoms/well-being”. The coders also searched for further studies on GoogleScholar by screening all papers that were indicated to have cited the papers that the primary search identified. Moreover, to obtain studies that were not easily accessible or unpublished, we sent out calls for data (via email lists and newsletters) through major associations in social and organizational psychology and management including the Society for Personality and Social Psychology (SPSP), the Society for Industrial and Organizational Psychology (SIOP), the European Association of Social Psychology (EASP), the Social and Organizational Sections of the German Psychological Society (DGPs), and the Society of Australasian Social Psychologists (SASP).

\section{Study Inclusion Criteria}

We included all published and unpublished studies reported in English if they reported any quantitative assessments concerning the relationship between individuals' social identification with either workgroup or organization and at least one health indicator. We included studies if the report was in English. In an attempt to include reports of studies in languages other than English, in our calls for data, we asked for results from any additional (published or unpublished) studies, which could be based on reports in other languages, as long as the authors sent us reports concerning the identification-health relationship in English.

To be included, studies had to fulfill the criterion of being based on explicit measures of social identification with either workgroup or organization (including standard identification 
scales and other scales that were constructed for the purpose of assessing identification; for a review, see Postmes et al., 2013). Studies were excluded if they measured other organizational constructs (such as commitment; for detailed discussions of conceptual differences, see Meyer, Becker, \& van Dick, 2006; Ng, 2015; van Knippenberg \& Sleebos, 2006). Moreover, studies also had to fulfill the inclusion criterion of assessing an explicit measure of psychological or physiological health and well-being including burnout (including its sub-dimensions emotional exhaustion, cynicism, and reduced accomplishment), subjective stress or strain, physical stress or symptoms including health complaints or symptoms, physiological functioning, general health, subjective well-being, work engagement, and positive and negative emotions at work.

Studies were excluded if they assessed other organizational outcomes such as job satisfaction, turnover, or performance (Riketta \& van Dick, 2005). Moreover, studies had to fulfill the inclusion criterion of being conducted and retrieved up to April 2014, while we did not set inclusion criteria for starting dates (i.e., studies could have been conducted any time prior to 2014). Moreover, studies that used any methodology (e.g., correlational, longitudinal, and experimental designs) were included but they had to provide statistical information about the quantitative assessment of the identification-health relationship. Studies were excluded if they used other assessments of this relationship (e.g., qualitative studies).

The search strategy based on the above inclusion and exclusion criteria yielded a total of 102 effect sizes based on 58 independent samples $(N=19,799)$ concerning the (workgroup and organizational) identification-health relationship. To provide a comprehensive and transparent description of the studies including the coding of variables (as described in more detail below), an overview of the studies is presented in Table 3.

\section{Coding Procedure}

We coded all variables that were relevant for the present analysis including author names, 
year of publication, publication status, sample size, effect size, and the type of sample. Moreover, we coded all potential moderators as discussed previously as well as several further variables for exploratory purposes including the particular identification scale that was used to assess identification, the study's methodology, the gender and age of participants, the status of their profession, and Inglehart-Welzel cross-cultural dimensions of the country in which study was conducted. All coded variables are described in more detail in what follows.

A team of four coders, all of whom had completed a university degree in psychology and received an induction about the meaning of the variables of interest, coded all variables. At least two coders coded any single variable. Discrepancies in coding were discussed between the coders and resolved by the author team. In cases where it was not possible to extract relevant data (because data were missing or the report was ambiguous), we contacted the authors via email and requested either the data or an indication of the nature of missing data (and sent out two additional reminders if authors did not respond within two weeks). We contacted the authors of 18 primary studies, all of whom responded.

To provide a more detailed description of the included studies, overall, 31 of the 102 effect sizes in the final sample (30.4\%) are based on items adapted from Mael and Ashforth's (1992) identification scale, 27 effect sizes $(26.5 \%)$ are based on items adapted from Doosje et al.'s (1995) scale, and 9 effect sizes (889\%) are based on items adapted from van Dick et al.’s (2004) scale. Following the use of these three scales, the use of other scales varied significantly. Another 4 effect sizes (3.9\%) are based on items adapted from Ellemers' (1993) scale, 3 effect sizes $(2.9 \%)$ each are based on items adapted from the scales by Haslam (2004), Postmes et al. (2013), and Sellers et al. (1998), 2 effect sizes (2.0\%) each are based on items adapted from the scales by Brown et al. (1986) and Leach et al. (2008), while the remainder are either based on items adapted from various other scales (e.g., Cameron, 2004) or were created for the purpose of 
the research with no scale used for more than one effect size.

Moreover, studies used a variety of different measures to assess health constructs.

Overall, 24 of the 102 effect sizes in the final sample (23.5\%) are based on scales that assess subjective well-being and general health (e.g., Goldberg, 1972; Warr, 1990), 22 (21.6\%) are based on scales and biological measures that assess physical stress or symptoms (e.g., Brähler, Hinz, \& Scheer, 2008; Patchen, 1970), 20 (19.6\%) are based on scales that assess burnout or subdimensions of it (e.g., Maslach \& Jackson, 1981; Singh, Goolsby, \& Rhoads, 1994), 17 (16.7\%) are based on scales that assess subjective stress (e.g., Cohen, Kamarck, \& Mermelstein, 1983; Parker \& DeCotiis, 1983), and 15 (14.7\%) are based on scales that assess positive or negative emotions at work. In line with the present theoretical focus and as discussed previously, we conduct moderation analysis by health valence and index and refrain from analyzing effect size strength as a function of particular health constructs - not least because of the variability in the assessed health constructs (and the variability in the scales within constructs) limits the meaningfulness of results. Nevertheless, we conducted an exploratory moderator analysis, which revealed that the relationship between identification and these different outcomes did not differ in strength. In what follows, we provide a detailed description of the coding of variables.

Country. We coded studies based on the country that a study was conducted in (i.e., the country that participants were residing in).

Sample. We coded the sample of participants as a function of participants' job or profession as described in the studies (e.g., whether the sample consisted of teachers, bank assistants, call center employees).

Publication status. We coded effect sizes as a function of publication status - recording whether an effect size was published or unpublished.

Identification focus. We coded effect sizes as a function of whether participants 
indicated their identification with a workgroup (or team, department) or their organization as a whole.

Health valence. To capture health valence, we coded whether health was measured in positive or negative terms - that is, whether an effect size referred to the presence of well-being (e.g., subjective health, psychological well-being, work engagement, positive emotions at work) or the absence of stress (e.g., strain, burnout, physical health symptoms, negative emotions at work). To render effect sizes comparable, for the purpose of the analyses we reverse-coded the sign of the effect size in the case of indicators of the absence of stress to denote health.

Health index. To denote health index, we coded whether the health indicator represented psychological (e.g., reported psychological well-being, stress, burnout) or physical health (e.g., reported or assessed physiological functioning, physical health, cortisol levels).

Identification scale. We coded the identification scale as a function of the inventory that was used to assess social identification. As described above, by far the most commonly used scales were Mael and Ashforth's (1992) scale (31 effect sizes, $k=19$ ) and Doosje et al.'s (1995) scale (26 effect sizes, $k=12$ ). We also coded effect sizes that used van Dick et al.'s (2004) scale (9 effect sizes, $k=4$ ). However, due to their low frequency of use, we coded all remaining scales into a fourth residual category.

Study methodology. We coded studies based on whether they employed a cross-sectional design, or a longitudinal or experimental design that manipulated social identification to address issues of causality. As the sample included only three studies that used experimental designs (designs identified as Research Design 1 by Cooper, Robinson, \& Patall, 2006) and only five studies that used longitudinal designs (Research Design 2), we combined studies that used experimental and longitudinal designs $(k=8)$ and compared them to studies that used correlational designs $(k=50$; Research Design 3). Experimental studies that manipulated other 
variables but assessed social identification were coded as cross-sectional designs for the present purposes and effect sizes were based on the zero-order correlations between identification and health measures.

Gender of participants. To denote participants' gender, we coded a study based on the proportion of female participants in the sample (as a percentage).

Age of participants. To denote participants' age, we coded the mean age of participants in a sample.

Status of profession. We coded studies based on the status of participants' profession by means of the Cambridge Social Class and Stratification Scale (CAMSIS; Lambert \& Prandy, 2014; Prandy, 1990; Sacker, Firth, Fitzpatrick, Lynch, \& Bartley, 2000; for a review on status and health, see Gallo \& Matthews, 2003). We used country-specific indices where they existed and if indices differed by gender, we weighted the sample score by the gender of participants in a sample. For studies conducted in countries for which there did not exist country-specific indices, we used the international CAMSIS scale. In samples that included distinct sets of professions, we weighted the score by the number of participants in each set and in samples that included participants from different countries, we weighted the score by country. For 11 studies, we were not able to code status because participants worked in a range of different jobs in various industries.

Inglehart-Welzel cross-culture dimensions. We coded studies as a function of the country's Inglehart-Welzel cultural value dimensions — the traditional/secular-rational dimension (reflecting a country's secular values) and the survival/self-expression dimension (reflecting a country's emancipative values; Inglehart \& Baker, 2000) — using the most recently updated data from Wave 6 (World Values Survey, 2014). If data for a given country was not available in the most recent wave, we used the data from the preceding Wave 5. Because there 
are no data available for Belgium and Greece in any of the waves, the sample size was reduced for this analysis $(k=54)$.

Shared social identification. We also coded the standard deviation $(S D)$ in social identification in samples in which participants shared membership, and reported identification with, the same single group as indicators of sharedness in social identification. These criteria were fulfilled in 21 effect sizes based on 16 independent samples $(N=8,179)$ of the identified studies assessing the social identification-health relationship. Fifteen samples assessed organizational identification and one sample assessed workgroup identification (all remaining studies that assessed workgroup identification provided indicators of identification from participants who were part of different workgroups and pooled data across participants in multiple workgroups). Scores were standardized across samples to form a 1 to 7-point Likert scale.

\section{Analytic Procedure}

Consistent with the majority of primary research that has reported correlations between social identification and health, we used mean-weighted $r$ as the effect size of choice. We analyzed effect sizes using Fisher's Z-transformation and for ease of interpretation we then converted all effect sizes into an $r$-statistic (see also Lipsey \& Wilson, 2001). We estimated the amount of variation in the effect size distribution by inspecting indicators of homogeneity of variance $(Q)$ and heterogeneity of variance $\left(T\right.$ and $\left.I^{2}\right)$. We also estimated the $95 \%$ prediction interval following recommendations and using the formula provided by Higgins, Thompson, and Spiegelhalter (2009). To perform the analyses, we used comprehensive meta-analysis version 3 from Biostat Inc. (Engelwood, New Jersey, USA).

Some studies reported multiple outcomes. Because effect sizes were not independent in such cases, we used the approach suggested by Cooper (1998) to account for non-independent 
effect sizes and combined non-independent effect sizes by averaging across them. In line with Hedges and Olkin's (1985) method, we correct for measurement bias due to sampling error by weighting effect sizes by sample size using a random-effects model (Borenstein, Hedges, Higgins, \& Rothstein, 2009; Cumming, 2014; Hunter \& Schmidt, 2000).

Furthermore, following recommendations by Ferguson and Brannick (2012) and Kepes, Banks, McDaniel, and Whetzel (2012) to use triangulation of methods to address publication bias, we used a number of different traditional and advanced techniques to estimate and correct for measurement and publication bias (for an overview, see also Borenstein et al., 2009). Specifically, we inspected (a) Orwin's (1983) fail-safe $N$ for effect size analysis to determine the number of studies with a correlation of zero that would be needed in file drawers to reduce any potentially significant effects to a small correlation of .05 , (b) a funnel plot asymmetry test (Egger, Smith, Schneider, \& Minder, 1997) to assess potential asymmetry in effect sizes and standard error (asymmetry would be indicative of publication bias), (c) trim and fill analysis (Duval \& Tweedie, 2000) to assess the unbiased point estimate of the effect size after adjusting for missing studies, (d) subgroup analysis by publication status to assess the extent to which the effect size in unpublished studies is significant and differs from that in published studies (Egger, Juni, Bartlett, Holenstein, \& Sterne, 2003; McAuley, Tugwell, \& Moher, 2000), (e) p-curve analysis to assess whether there the set of studies have evidential value (whether there is evidence of $p$-hacking) and whether the evidential value is inadequate (Simonsohn, Nelson, \& Simmons, 2014), and (f) cumulative meta-analysis that involves sorting studies in the sequence from largest to smallest before performing cumulative meta-analysis with the addition of each study to assess the extent to which the effect size changes as smaller studies are added (if effect size does not shift, then there is no reason to suspect bias; Borenstein et al., 2009).

To assess the impact of the present categorical moderators, we again used a mixed-effects, 
rather than a fixed-effects, model. For the analyses of categorical moderators, the variance across the subgroups was pooled (i.e., we do not assume that the variance within each level of a categorical moderator should differ from each other). We used the $Q$ statistic to determine whether the variation in effect sizes was greater than expected due to sampling error. To examine whether a categorical moderator accounted for variability in effect sizes, we conducted subgroup analyses (Borenstein et al., 2009).

The data structure was somewhat complex in that for three moderators (identification focus, health valance, and health index), some studies included dependent subgroups (i.e., they included measures of both values of a moderator and thus observations within each level of the moderator are not independent in these studies). Dependent subgroups are particularly informative in assessing moderation to the extent that the two levels of a moderator are correlated with each other. To account for non-independence of observations, we followed procedures outlined by Borenstein and colleagues (2009) by calculating a difference score in the identification-health relationship as a function of the level of a moderator while taking into consideration the strength of the correlation between the two levels of a moderator as found in a particular study. We combined the resulting difference score of dependent samples with the difference score of independent samples to calculate overall variability in effect size as explained by a moderator.

To assess whether the continuous moderators affected the identification-health relationship, we performed univariate meta-regression by means of method of moments to estimate parameters (Borenstein et al., 2009). To analyze the impact of social status and sharedness in identification, we performed meta-regression on the sub-sample in which data for these variables were available.

In addition to univariate moderation analyses, we conducted multiple regression analysis 
by means of meta-regression to estimate the combined variance of the distribution of true effect sizes that can be explained by the moderators that the univariate analysis revealed as significant (Borenstein et al., 2009). Because the data had a complex structure (such that categorical moderators included a set of dependent subgroups that furthermore differed between the moderators) that does not allow us to estimate explained variance at a sample level, we specified a meta-regression model that assumed independence between outcomes within a sample for this purpose. This model provides a conservative test of the strength of a moderator to the extent that the categories of a moderator are in fact correlated (Borenstein et al., 2009), and we thus recommend interpreting these results with caution. To account for the fact that only a sub-sample of studies $(k=16)$ provided data concerning shared identification, we ran a separate a metaregression model that included $S D$ in social identification only to estimate explained variance in effect size distribution in this sample.

\section{Results}

\section{Summary Effect Analyses}

We estimated the overall effect size of the relationship across all 102 effect sizes based on the 58 independent samples $(N=19,799)$ that examined social identifications in organizations and health outcomes (as presented in Table 3). Results of a random-effects model analysis indicated that the mean-weighted relationship between social identification and health was positive with an effect size of $r=.21,95 \%$ CIs: [.17, .25]; $Z=10.11$. Figure 1 presents a forest plot displaying effect sizes, confidence intervals, and weights of independent samples and the effect size distribution around the summary effect. Analysis indicated that the overall heterogeneity in effect sizes across samples was larger than would be expected due to sampling error, $Q(57)=406.61, p<.001$. Moreover, a substantial amount $\left(I^{2}=85.98 \%\right)$ of the observed variation was due to real differences in true effect sizes between studies (i.e., $14.02 \%$ of the 
observed variation was due to sampling error). Furthermore, there was significant absolute dispersion in true effect sizes $(T=.138) .{ }^{1}$ Estimation of the approximate $95 \%$ prediction interval (Higgins et al., 2009) indicates that there is a probability of $95 \%$ that the true effect in a new study would fall within a range of -.07 to .46 .

\section{Measurement Correction and Publication Bias Analyses}

In addition to using random-effects model analysis to estimate a weighted-effect size, we used several advanced techniques to address publication bias. An overview of the key questions about the robustness of the evidence and answers provided by the results of the various analyses that address measurement and publication bias is presented in Table 4.

Fail-safe $N$ effect size analysis. Fail-safe $N$ for effect size analysis (Orwin, 1983) indicated that 217 studies in file drawers with a mean correlation of zero would be needed to reduce the present effect size to a small correlation of .05 . Given that 58 studies were identified in the present meta-analysis, it is unlikely that 217 studies (more than three times as many identified studies) were missed.

Funnel plot asymmetry test. Visual inspection of the funnel plot indicated that there were no particular causes for concern about asymmetry as a function of effect size and standard error, and the funnel plot asymmetry regression test (Egger et al., 1997) indicated that there was no evidence that the funnel plot was asymmetrical (intercept, $b=-1.02$, 95\%CIs: $[-2.37, .33]$, $t(56)=1.51, p=.14)$. Overall, these analyses suggest that there is no evidence of publication bias due to small study effects.

Trim and fill method. The trim and fill approach (Duval \& Tweedie, 2000) estimates the number and magnitude of effect sizes missing due to publication bias before then correcting the estimate of the summary effect size by imputing any missing effect sizes. This approach identified some asymmetry in effect sizes to the left side of the mean due to potential 
underreporting of effect sizes below the point estimate. However, an adjustment for missing studies by imputing six missing studies indicated an unbiased estimation of the social identification-health relationship of a similar effect size, $r=.18,95 \%$ CIs: $[.14, .22]$. This unbiased effect size has the same substantial implications as the effect size estimated by the random-effects model, thereby providing no evidence that the effect size was impacted by bias.

Analysis by publication status. We conducted subgroup analysis as a function of publication status by estimating effects sizes in published and unpublished studies. Results indicated a significant positive identification-health relationship on the basis of both published effect sizes, $r=.23,95 \%$ CIs: [.18, .28]; $Z=9.15$, unpublished effect sizes, $r=.16,95 \%$ CIs: [.07, $.24] ; Z=3.70$. The effect size was larger in published effect sizes but the between-group difference was not greater than expected due to sampling error, $Q(1)=2.30, p=.317$, indicating no evidence that the strengths of the effect sizes differed as a function of publication status. Further inspection of the data indicated that the overall lower estimate of the effect size was largely due to one study by Galang and Jones (2014) that found a contrasting moderate-to-strong negative identification-health relationship of $r=-.41,95 \%$ CIs: $[-.59,-.19]$, which given the small sample of unpublished effect sizes $(k=14)$, has a large influence on the estimate of the overall effect size. Analysis without this study leads to a significant increase in the estimated effect size based on unpublished effect sizes, $r=.19,95 \%$ CIs: [.11, .27]; $Z=4.45$, and again a non-significant difference between the effect size based on publication status, $Q(1)=.83, p=$ .659 .

$\boldsymbol{P}$-curve analysis. We $p$-analyzed the set of findings (Simonsohn et al., 2014) to examine whether or not the set of findings have evidential value as a result of selective reporting (in particular, $p$-hacking). Because the $p$-values in studies that report multiple dependent variables are not independent of each other, we followed Simonsohn et al.'s recommendations to focus 
only on the $p$-value that was reported first (in a correlation table and if there was none, in the text) and then ran another robustness analysis using the $p$-value that was reported last. One effect size from Frisch et al. (2014) could not be used in $p$-curve analysis because the study design was an experimental attenuation interaction design and inclusion of the simple effect for identification on health would bias p-curve analysis (Simonsohn et al., 2014). Results are presented in Figure 2. The figure shows no uptick in the $p$-curve at the level of .05 (which would indicate some level of $p$-hacking). Both the full $p$-curve (testing $p$-curve against threshold $p<.05$ ) and the half $p$-curves (testing $p$-curve against threshold $p<.025$ ) are significantly right-skewed at less than $p<.10$ : full $p$-curve: $Z=21.24, p<.0001$; half $p$-curve: $Z=22.09, p<.0001$. This indicates that the set of studies contains evidential value and that there is no evidence of $p$-hacking or ambitious $p$ hacking (up to $p<.025$; Simonsohn, Simmons, \& Nelson, 2015). Furthermore, the $p$-curve is not flatter than would be expected if the studies had a power of $33 \%$, full $p$-curve: $Z=15.18, p>$ .9999 ; half $p$-curve: $Z=19.23, p>.9999$, thereby providing no evidence that the existing evidential value is inadequate (i.e., that effects are too small given the size of the samples). A separate robustness test using the $p$-value associated with the effect size that was reported last in studies that reported multiple effect sizes indicated virtually identical results. Both the full pcurve and the half-curve are significantly right-skewed, full $p$-curve: $Z=21.70, p<.0001$; half $p$ curve: $Z=22.09, p<.0001$, indicating that the set of studies contain evidential value. Results also indicate that the $p$-curve is not flatter than a curve that would be expected if the studies were powered at $33 \%$, full $p$-curve: $Z=15.62, p>.9999$; half $p$-curve: $Z=19.23, p>.9999$, again providing no evidence to suggest that the evidential value of the suite of studies under consideration is inadequate.

Cumulative meta-analysis. We conducted cumulative meta-analysis to inspect the studies' effect sizes as a function of their sample size (Borenstein et al., 2009). We first inspected 
the data visually as shown by the cumulative forest plot in which studies are sorted by sample size and this is presented in Figure 3. As can be seen from this figure there was no evidence of a drift of the effect size towards the right as smaller studies are added (towards the bottom of the plot), thereby suggesting no evidence of bias due to small-study effects. To investigate this further, we conducted meta-regression with sample size as a predictor of the effect size. Results provided no evidence that studies' estimated effect size was related to sample size, $b<.0001$, $95 \%$ CIs $[-.0001, .0001], Z=.79, Q(1)=.63, p=.429$. Estimation of the effect size based on the largest samples $(k=29)$ yielded an effect size, $r=.20,95 \%$ CIs: $[.15, .25] ; Z=7.85$, that has the same substantive implications as the summary effect size generated by the random-effects model based on the total sample. Overall, then, estimation and correction for measurement and publication bias indicates that publication bias has negligible impact on the core findings we report.

\section{Categorical Moderation Analyses}

Identification focus: Workgroup versus organizational identification. Results concerning all categorical moderators are presented in Table 5. First, we examined the extent to which the effect sizes between organizational identification and health and between workgroup identification and health differed in strength. Analysis revealed that organizational identification was positively related to health, $r=.21$, 95\%CIs: $[.17, .26] ; Z=9.20$, and that workgroup identification was also positively related to health, $r=.21,95 \%$ CIs: $[.14, .28] ; Z=5.90$. The variance between the groups of studies was not greater than could be expected due to sampling error and did not differ statistically from zero, $Q(1)=.14, p=.706$, suggesting that there was no evidence that the strengths of the effect sizes differed from each other.

Health valence: Absence of stress versus presence of well-being. Analysis indicated that the relationship between social identification and the absence of stress was positive, $r=.18$, 
95\%CIs: [.12,.23]; $Z=6.43$. The association with the presence of well-being was also positive, $r$ $=.27,95 \%$ CIs: $[.22, .33] ; Z=9.37$. Overall, there was evidence that the variance between the groups was greater than would be expected on the basis of sampling error, $Q(1)=7.71, p=.005$, suggesting that the relationship between social identification and the presence of well-being was stronger than the relationship between social identification and the absence of stress.

Health index: Physical versus psychological health. Analysis indicated that the association between social identification and psychological health was positive, $r=.23,95 \%$ CIs: $[.18, .28] ; Z=9.44$. The same was true for the association between social identification and physical health, $r=.16,95 \%$ CIs: [.10, .22]; $Z=5.39$. The between-group variance was significantly greater than expected due to sampling error, $Q(1)=4.87, p=.027$, indicating that social identification was more strongly associated with psychological than physical health indices.

Identification scale. The social identification-health relationship varied as a function of (dummy coded) identification scale, $Q(3)=9.80, p=.020$. Analysis revealed that the relationship was strongest in samples that employed the Doosje et al. (1995) scale, $r=.34$, 95\%CIs: [.25, .43]; $Z=6.98$, and stronger than in samples that used the Mael and Ashforth (1992) scale, $r=.18$, 95\%CIs: [.11, .24]; $Z=5.05$, the van Dick et al. (2004) scale, $r=.17$, 95\%CIs: [.02, .32]; $Z=$ 2.22, or other identification scales, $r=.18,95 \%$ CIs: $[.12, .25] ; Z=5.54$. To examine the robustness of the identification-health relationship, we conducted additional sensitivity analysis excluding effect sizes using the Doosje et al. (1995) scale $(k=46)$. This revealed an overall effect size of, $r=.18,95 \%$ CIs: $[.14, .22] ; Z=7.99$ - an effect size that has the same substantive implications that the effect size revealed by the summary random-effects model.

Study methodology. The social identification-health relationship was positive for studies that relied both on experimental and longitudinal designs, $r=.13$, 95\%CIs: [.01, .24]; $Z=2.11$, as 
well as those that relied on cross-sectional designs, $r=.22,95 \%$ CIs: $[.18, .26] ; Z=10.04$. The effect size was larger for correlational studies but the between-group difference was not greater than expected due to sampling error, $Q(1)=2.37, p=.124$.

\section{Continuous Moderation Analyses}

Gender. Analysis revealed that the social identification-health link was weaker to the extent that the proportion of female participants in the sample increased, $b=-.0028,95 \%$ CIs $[-$ $.0047,-.0010], Z=3.05, Q(1)=9.28, p<.001$.

Age. Analysis of the slope of the mean age did not differ statistically from zero, $b=$ $.0019,95 \%$ CIs $[-.0033, .0071], Z=.72, Q(1)=.52, p=.510$, providing no evidence that the social identification-health link was moderated by age.

Status. To examine the extent to which social status of a job moderated the social identification-health relationship, we analyzed all samples that afforded the possibility of coding for this variable $(k=47, N=17,977)$. The point estimate and confidence intervals of the estimation of the slope of social class of the job was not statistically significant, $b=-.0022$, $95 \%$ CIs $[-.0051, .0006], Z=1.52, Q(1)=2.31, p=.128$, indicating that there was no evidence that the social identification-health relationship was moderated by the social status of participants' job.

Inglehart-Welzel culture dimensions. We ran separate analysis to examine the extent to which the social identification-health relationship was moderated by a country's traditional/secular values and survival/emancipative values $(k=54)$. There was no evidence that the relationship was moderated by traditional/secular values, $b=-.7982,95 \%$ CIs $[-1.8445$, $.2481], Z=1.50$; or survival/emancipative values, $b=-.0070,95 \%$ CIs $[-.7167, .7027], Z=.02 .^{2}$

Shared social identification. To assess the extent to which sharedness in identification moderated the social identification-health relationship, we analyzed all samples where 
participants shared membership in, and indicated their identification with, the same group $(k=$ $16, N=8,179)$. The point estimate and confidence intervals of the estimation of the slope of $S D$ in identification was negative, $b=-.424,95 \%$ CIs $[-.65,-.22], Z=3.97, Q(1)=15.74, p<.001$, indicating that the social identification-health link was moderated by $S D$ in identification such that the positive relationship between social identification and health became weaker to the extent that $S D$ in social identification decreased. Reversing the signs, this suggests that the positive association between social identification and health became stronger as sharedness in identification among group members increased.

We conducted further sensitivity analysis by controlling for the sample's mean level of identification (standardized to a 1 to 7-point scale) in order to examine whether effects of sharedness are in fact driven by the mean level in identification (Harrison \& Klein, 2007; see also Liao, Liu, \& Loi, 2010; Steffens, Shemla, Diestel, \& Wegge, 2014). Analysis indicated that mean social identification did not significantly moderate the social identification-health relationship, $b$ $=.02,95 \%$ CIs $[-.10, .15], Z=.37$, while the effect of $S D$ in social identification remained largely unchanged, $b=-.39,95 \% \mathrm{CIs}[-.72,-.07], Z=2.37$. Overall, these results suggest that there is limited evidence that the moderation of the social identification-health relationship by $S D$ in identification was accounted for by mean level of identification.

\section{Multiple Regression Analyses}

We conducted multiple moderator analysis to estimate the combined variance that can be explained by the moderators that the previous analysis revealed to be significant (Borenstein et al., 2009). The regression model that included all reliable moderators health valence, health index, identification scale (as dummy coded variables), and gender, was significant, $Q(6)=$ $35.25, p<.001, R^{2}=.115$, indicating that overall the moderators accounted for $12 \%$ of the between-study variance in effect sizes (i.e., of the distribution of true effect sizes across studies). 
When controlling for each other, the regression weights were overall very similar to those revealed by univariate analyses: health valence $(b=.059,95 \%$ CIs $[-.012, .130], Z=1.63)$, health index $(b=.075,95 \%$ CIs $[-.008, .158], Z=1.77)$, identification scale $(Q[3]=15.24, p=.002)$, and gender $(b=-.0026,95 \%$ CIs $[-.0041,-.0012], Z=3.64)$.

The overall regression model on the sub-sample of studies concerning $S D$ in identification was significant, $Q(1)=15.74, p<.001, R^{2}=.565$, explaining $56.5 \%$ of the between-study variance in effect sizes. When mean identification was added, the overall model was also significant, $Q(2)=14.87, p=.001, R^{2}=.520$, accounting for $52.0 \%$ of the between-study variance in effect sizes (parameters of the explained variance can be lower in models with a greater number of moderators due to imprecision in estimating parameters; Borenstein et al., 2009). ${ }^{3}$

\section{Discussion}

The present research provides a quantitative review of an increasingly large field of research that has interrogated the relationship between social identifications in organizations on the one hand and individuals' health on the other. The present study provides meta-analytic results from primary published and unpublished studies that indicate that social identifications in organizations are overall positively related to individuals' health. Moreover, results reveal an instructive estimation of the precise summary magnitude of the social identification-health relationship of $r=.21$, which is of small-to-moderate size (Cohen, 1992). On the whole, results suggest that rather than being related to employees' exhaustion, social identification with (a) a workgroup and (b) an organization is instead positively related to employees' invigoration (thereby providing support for an invigoration hypothesis).

We used several methods to estimate and correct for measurement and publication bias in the identified set of studies. Fail-safe $N$ for effect size analysis (Orwin, 1983) indicates that 217 
unidentified samples (more than three times the number of identified samples) from the file drawer with a correlation of zero would be needed to reduce the effect size to a small size of $r=$ .05. The funnel plot asymmetry test (Egger et al., 1997) revealed no evidence of publication bias as shown by a relationship between a study's effect size and standard error, while the trim and fill method (Duval \& Tweedie, 2000) revealed an unbiased effect size of a similar size of $r=.18$ after imputing potentially missing studies. Analysis of the set of studies by publication bias (Egger et al., 2003) indicated a significant positive effect size in both unpublished and published studies and no statistical evidence that the effect size differed as a function of publication status. Furthermore, $p$-curve analysis (Simonsohn et al., 2014) revealed that the set of samples had evidential value (showing no evidence of $p$-hacking across the samples), while yielding no evidence that the evidential value of the set of studies was inadequate. Finally, cumulative metaanalysis (Borenstein et al., 2009) furnished no evidence of publication bias due to small-study effects (as shown by no evidence of a drift of the effect size as smaller studies are added to the analysis), while analysis based on studies with larger sample sizes yielded an effect size of $r=$ .20 - a magnitude that is similar to that of the summary effect size and that has the same substantive implications. In sum, results across the various techniques that estimate and correct for measurement and publication bias reveal negligible impact of publication bias on the estimated summary effect size in the present set of samples.

In addition to estimating the magnitude of the global summary effect and correcting for measurement and publication bias, the present meta-analysis also revealed substantial variation in effect size distribution. Accordingly, we examined several novel and theoretically relevant variables as potential boundary and qualifying conditions of the observed relationship between social identification and health. Here there was no evidence that the strength of this relationship varied depending on the focus of identification (with a workgroup versus an organization). 
However, results indicate (a) that social identification was associated more strongly with (positive) experiences of health than with the absence of (negative) experiences of ill-health, and that the identification-health relationship was (b) stronger for psychological than physical health, (c) stronger in samples that used the Doosje et al. (1995) social identification scale (rather than other identification scales such as the Mael \& Ashforth, 1992, or the van Dick et al., 2004, scale), and (d) stronger to the extent that the proportion of female participants in the sample decreased. Finally, there was evidence that the social identification-health relationship became (e) more pronounced with increasing levels of sharedness in identification.

\section{Social Identification in Organizations as a Backbone to Individuals' Health}

The present research substantiates assertions that individuals' self-categorization in terms of a workgroup and an organization has implications for stress and well-being in the workplace (van Dick \& Haslam, 2012). At the same time, it extends our understanding of previous empirical studies by providing a more comprehensive, precise, and quantitative assessment of the identification-health relationship. Here the evidence reveals that by and large individuals' strength of internalization of a workgroup and organization-based membership relates to their experience of diminished discomfort and stress as well as enhanced comfort and well-being. In this way, the present research expands upon a wider literature that has asserted that health and well-being are influenced by social factors in general and by issues of group membership and identity in particular (Adler, Lodi-Smith, Philippe, \& Houle, 2016; Cruwys et al., 2014; Diener \& Biswas-Diener, 2008; Drury, 2012; Helliwell \& Putnam, 2004; Jetten et al., 2012; Jetten, Haslam, Haslam, Dingle, \& Jones, 2014; Sani et al., 2012). In particular, in providing meta-analytic support for an invigoration hypothesis it lends substance to the claim that overall social identification is best conceptualized as a resource rather than a liability in relation to people's health and well-being at work. 
Previous research on social identification in organizational contexts has focused largely on workgroup and organizational identification as contributors to classic work-related outcomes such as motivation, in-role and extra-role performance, or turnover intentions ( $\mathrm{Ng}, 2015$; Riketta, 2005; Riketta \& van Dick, 2005; van Dick, 2004; van Knippenberg \& van Schie, 2000) but had paid far less attention to the role these play to the domain of health (Jetten et al., 2012). As well as complementing research that has advanced our understanding of motivation and performance in organizational contexts, these findings are particularly timely as research has started to point to ways in which people's health is a building block for subsequent performance and success (Lyubomirsky et al., 2005).

Speaking to the literature on health in organizations (Lundberg \& Cooper, 2011), findings indicate that social identification is an energizing source, whose significance aligns with (and is at least as marked as in the case of) resources that other meta-analyses have pointed to, such as social support (Thoits, 1995; Viswesvaran, Sanchez, \& Fisher, 1999), hardiness (Eschleman, Bowling, \& Alarcon, 2010), humor in the workplace (Mesmer-Magnus, Glew, \& Viswesvaran, 2012), or the promotion of individuals' mindfulness, mediation, or relaxation (Grossman Niemann, Schmidt, \& Walach, 2004; Richardson \& Rothstein, 2008). At the same time, the present findings have unique theoretical and practical value because they suggest that individuals' stress and health at work are grounded not just in individuals' personal capabilities and shortcomings but also in groups and organizations as a whole. In particular, it would appear that organizations that seek to foster the health of their workforce are likely to be more successful if they (a) allow members to contribute to and shape organizational identity so that people are able to feel 'at home' in the workplace (Knight \& Haslam, 2010b) or (b) create structures that facilitate the development of identities associated with lower-level workgroups (Hornsey \& Hogg, 2000). 


\section{Boundary Conditions of the Identification-Health Relationship}

It is worth noting that even though the observed relationship between social identification and health was positive, there was significant variation in its strength. To help understand the nature and source of this variability, we examined the role of a range of theoretically important factors. In what follows, we focus on those factors that have greatest theoretical relevance and on those that exploratory analyses revealed as significant boundary and qualifying conditions of the identification-health relationship.

Identification focus: Workgroup and organizational identification. Analysis revealed that individuals' health was positively related to their social identification with both their workgroup and their organization. In this regard, literatures on salience of more proximal groups (Ashforth \& Johnson, 2001; van Knippenberg \& van Schie, 2000) and group socialization (Carron \& Spink, 1995; Moreland \& Levine, 2001) might have led one to expect that identification with a workgroup would be associated with stronger health effects; while other work on stability and continuity (Albert \& Whetten, 1985; Sani, 2008) as well as public regard of collectives (Dutton et al., 1994; Luhtanen \& Crocker, 1992) might have led one to expect the opposite. Overall, however - perhaps because these competing influences are equally important — the present findings reveal that the strength of the identification-health relationship did not differ as a function of identification focus but was of comparable magnitude for organizational identification $(r=.21)$ and for workgroup identification $(r=.21)$.

Health valence: Presence of well-being and absence of stress. Our analysis provides clear evidence that social identification is related to the absence of (negative) forms of ill-health as well as the presence of (positive) forms of well-being. Nevertheless, social identification had somewhat stronger benefits for the enhancement of salutogenic aspects of health than for the prevention of pathogenic ones. More broadly, in indicating that social identification feeds more 
strongly into the promotion of what is 'good for us' than into the prevention of what is 'bad for us', these findings support previous work which has made the point that the absence of stress is not equivalent to the presence of well-being (Diener, 2000; Schaufeli, Salanova, González-Romá, \& Bakker, 2002; Seligman \& Csikszentmihalyi, 2000). More specifically, findings are consistent with a psychological conception of positive human health (Ryff \& Singer, 1998; Thoits, 1994) and phenomenological accounts of social identification which suggest that increases in identification capture increases in positive experiences (Haslam et al., 2009) and are therefore related particularly strongly to positive forms of well-being. As a corollary, although increases in identification also involve the amelioration of suffering (Branscombe et al., 2009), such consequences are less pronounced (in part too because the absence of identification is more likely to relate to a lack of positive experiences rather than to the presence of negative ones).

Indeed, it is possible that compared to the promotion of well-being that relates more strongly to social identifications in organizations, the prevention of ill-health may depend to a larger degree on factors other than identification with a single work-related entity (e.g., identification with other non work-related groups as well as multiple group memberships; see Cruwys et al., 2013; Iyer, Jetten, Tsivrikos, Postmes, \& Haslam, 2009; van Steenbergen, Ellemers, Haslam, \& Urlings, 2008). Similarly, it is conceivable that increasing levels of disidentification (i.e., actively distancing self from the group; Kreiner \& Ashforth, 2004; Pratt, 2000) are more strongly related to the presence of unease, discomfort, and stress than to the absence of ease, comfort, and well-being. These are interesting lines of inquiry that future research should address more programmatically.

Health index: Physical and psychological health. Consistent with the notion of compatibility in levels-of-analysis (Fishbein \& Ajzen, 1974; Riketta \& van Dick, 2005), the present findings indicate that identification-health relationships are particularly strong to the 
extent that social identification relates to the psychological experience of health. Nevertheless, it is noteworthy that the identification-health link was also positive (albeit weaker) in relation to physical health (e.g., as assessed by physiological indicators). In the first instance, we would note that common-method variance may have contributed to this differential association (Podsakoff, MacKenzie, Lee, \& Podsakoff, 2003). However, it seems unlikely that common-method variance can account fully for this divergence not least because some studies relied on experimental designs and some of the physical health indicators relied on self-report (e.g., symptom checklists). Taken as a whole, rather than providing support for a bio-medical model of stress and well-being, findings thus demonstrate the usefulness of bio-psycho-social models which suggest that physical and physiological markers of health are determined in no small part by the broader social-psychological environment in which people find themselves (Cacioppo, Berntson, Sheridan, \& McClintock, 2000; Jetten et al., 2012; Helliwell \& Putnam, 2004).

Shared social identification. Finally, the present research breaks new ground in being the first to review a large empirical domain in a way that allowed us to investigate the extent to which shared social identification has particular significance for stress and well-being. Here findings indicate that people's experience of better health was particularly strongly associated with increased social identification when that social identification was shared among group members (accounting for more than $52 \%$ of the between-study variance in this sample, while also indicating that this finding was not driven by the mean level of identification). In this way, it appears that in addition to being influenced by personal experiences of the relationship with a collective entity, individuals' health and well-being are also shaped by other group members' experiences of their relationship with that entity.

Speaking to the construct of social identification itself, these findings also underscore the point that sharedness infuses this with a qualitatively different meaning, and hence that this is an 
important (but typically overlooked) aspect of social identification (Jans et al., 2015; Tajfel, 1981; see also Alnabulsi \& Drury, 2014; Pandey, Stevenson, Shankar, Hopkins, \& Reicher, 2014; Stott \& Drury, 2000). Indeed, the social component of identification matters not only because individuals internalize a (social) group as part of their self-concept but also because, and to the extent that, identification shifts from being a merely personally referenced experience to one that is collectively shared.

Additional findings. The vast majority of studies employed cross-sectional designs. Nevertheless, it is important to note that the social identification-health relationship was consistently positive across different methodologies such that the relationship was found both in studies that employed cross-sectional designs and in those that employed experimental or longitudinal designs, providing some evidence of directionality. Moreover, the relationship was stronger the greater the proportion of male participants in a sample. We cannot know with any certainty why this was the case, but only speculate. Nevertheless, in the first instance it is worth noting this finding could be seen as surprising in light of evidence that women tend to have larger social support networks than men (Kendler, Myers, \& Prescott, 2005). At the same time, this finding is in line with claims and evidence that men tend to place particular emphasis on their collective self and that, compared to female workers, males tend to show stronger collective identification and greater satisfaction with group tasks (Zhang, Chen, Chen, Liu, \& Johnson, 2014). It is also entirely possible that these gender differences reflect the fact that many workplaces are stereotypically masculine (e.g., in terms of their culture) and that women are often a minority within organizational contexts. These two factors mean that female workers routinely encounter more obstacles to identification and experience greater difficulty 'fitting in' than their male counterparts (Peters, Ryan, Haslam, \& Fernandes, 2012).

Finally, the identification-health link was strongest in studies that used the Doosje et al.'s 
(1995) identification scale. This may in part be due to the fact that one of the four items in this scale taps into satisfaction with membership in a group ("I am glad to be a member of the group"), which may have a particularly strong bearing on people's experiences of general health and well-being than other identification items. At the same time, and perhaps less evident at first sight, this stronger association may also in part be due the fact that two of the items refer to group members rather than the group as a whole ("I identify with other group members"; "I feel strong ties with other group members"; see also Karasawa, 1991), while most other scales refer only to the group as a whole (including the most widely used scale by Mael \& Ashforth, 1992, and the scale by van Dick et al., 2004). It may be the case that items referring to group members are related more strongly to health and well-being because they are more likely to tap into intragroup attraction than intergroup relations. Indeed, the literature on social exclusion demonstrates that when individuals feel that they are socially excluded by other close individuals this can have devastating consequences on health and well-being (Leary, 1990; MacDonald \& Leary, 2005). In any event, these findings suggest that this issue of the relative importance of intragroup attraction and intergroup relations for health is an important issue for future research to address and resolve.

\section{Limitations and Roadmap for Future Research}

Elaborating on aspects of the forgoing discussion, in what follows, we highlight five themes that emerged from the present findings and that will be important for future research to address. First, the global effect sizes revealed in the present analysis support the notion that social identification is associated with individuals' feelings of vitalization rather than exhaustion. While this appears to be true in general terms, it would nevertheless be interesting to understand the precise processes that underpin this relationship by disentangling the various elements that are bound up with social identification and that may have differential bearing on people's health and well-being. Specifically, the relationship between increasing social identification and health is 
likely to be complex such that it might be determined not only by the specific beliefs, norms, values, and ideals that a workgroup or organization promotes (which may be more or less conducive to a healthy habits; Oyserman et al., 2007; Tarrant et al., 2012) but also by the (negative or positive) treatment that it receives from other groups (Amiot, Terry, \& Callan, 2007; Jetten, Branscombe, Schmitt, \& Spears, 2001; Pascoe \& Smart Richman, 2009; Postmes \& Branscombe, 2002; for a recent review see Schmitt, Branscombe, Postmes, \& Garcia, 2014). More generally, it is likely that increasing identification feeds into a health-promoting pathway by enhancing an individual's sense of purpose, belonging, and collective self-efficacy (Cruwys et al., 2014), as well as by laying the foundations for the receipt and positive construal of social support (Levine et al., 2005; Platow et al., 2007). On the other hand, elevated social identification in the workplace may also feed into a health-diminishing pathway to the extent that it compromises individuals' capacity to build and maintain memberships in other relevant groups (van Steenbergen et al., 2008). To provide us with a richer understanding of the various implications of identification for health, there would clearly be value in research that disentangles these processes as well as investigates their simultaneous effects (e.g., by means of elaborate experimental and longitudinal designs that control for the influences of each other).

Second, the notion of sharedness as a consequential part of people's identification with a group (in addition to personally referenced identification) strikes us as particularly interesting and hence worth exploring in more detail. Nevertheless, one of the obvious reasons why this aspect of social identification has tended to be overlooked in previous research is that most standard identification scales assess identification in terms of individual group members' selfcategorization as group members without explicit reference to their sense of shared identification (e.g., Abrams et al., 1998; Brown et al., 1986; Cameron, 2004; Doosje et al., 1995; Ellemers et al., 1999; Jackson, 2002; Leach et al., 2008; Mael \& Ashforth, 1992; Mael \& Tetrick, 1992; 
Roccas et al., 2008; for a review, see Postmes et al., 2013). Thus while identification measures are highly reliable and clearly provide extremely valuable information in their standard form (Ashforth et al., 2008), the present findings suggest that important information might be lost to the extent that these fail to assess actual sharedness in identification. From a methodological point of view, then, to provide a more in-depth understanding of the importance of sharedness, it would be fruitful to employ multi-level approaches as well as to develop new forms of assessment that tap into sharedness of social identification. It is also important to note that in the present analysis we investigated actual sharedness in identification. In this regard, there would be value in future work that examines when and why actual sharedness goes hand in hand with (or diverges from) an individual's sense of sharedness as well as the unique and overlapping consequences of both for their experience of health.

Third, there is a need for more studies that employ experimental and intervention as well as longitudinal designs to examine the impact of organizational identifications on individuals' health. In this regard, future research should expand our understanding of the various factors that can be harnessed (e.g., collective empowerment, collective decision making) with a view to fostering social identification and health (e.g., Gleibs et al., 2011; Haslam, 2014). Indeed, given that by and large organizational identification can be seen as a health resource at work, it appears that organizations also have some responsibility for creating workspaces that are not only motivating but also healthy. In this regard, future research is needed to shed light on the capacity for social and organizational policies as well as job and work design (Parker, 2014) to build social identification (e.g., in ways formulated by the ASPIRe model; Haslam, Eggins, \& Reynolds, 2003).

Fourth, the majority of studies that have investigated the relationship between social identification in the workplace and health have focused on social identification as a uni- 
dimensional construct. Very few studies, and too few for a systematic analysis, assessed subdimensions of identification in relation to people's health. However, there is evidence that social identification comes in different forms (such as ambivalent identification; Ashforth, Rogers, Pratt, \& Pradies, 2014; Kreiner \& Ashforth, 2004; Pratt, 2000) and can be conceptualized as comprising different qualities and sub-dimensions (e.g., Ashmore, Deaux, \& McLaughlin-Volpe, 2004; Bergami \& Bagozzi, 2000; Cameron, 2004; Jackson, 2002; Leach et al., 2008). In future work, examination of various sub-components and forms of identification may be interesting because it is conceivable that different components have a differentiated impact on particular health outcomes (cf. Harris \& Cameron, 2005). To provide a more complete understanding of the identification-health relationship, future research should therefore attempt to disentangle the ways in which health is influenced by the multi-faceted forms that social identification can take.

Fifth, although a body of research and theory indicates that health is influenced by social identification with a single group at work, little research has examined health as a function of social identification in relation to various other (work and leisure) groups (Ramarajan \& Reid, 2013; van Steenbergen et al., 2008). This is important because emerging evidence suggests that people's well-being as well as their capacity to adjust to new life circumstances is determined by the multiple identities that they see as important to self (Cruwys et al., 2013; Haslam et al., 2008; Jetten et al., 2012; Ramarajan, 2014; van Dick, van Knippenberg, Kerschreiter, Hertel, \& Wieseke, 2008). In relation to individuals' health in organizations, future research might examine in more detail the health consequences that flow not just from workplace identification but also from simultaneous identifications with other relevant groups (e.g., recreational, religious, family groups) as well as the interrelationships between multiple identities.

\section{Conclusion}

The present meta-analysis is the first to provide a comprehensive quantitative examination 
of the large body of empirical data on the relationship between social identifications and health in organizations. In this, it helps clarify the question of the extent to which increased social identification with a workgroup and with an organization has beneficial or detrimental implications for individuals' health. Considered as a whole, evidence indicates that both workgroup and organizational identification are associated with individuals' experience of reduced strain and burnout as well as greater health and well-being. Yet, beyond these main effects, the present analysis also uncovers a range of important factors that fortify or attenuate the invigorating impact of such identification.

The present meta-analysis is set against the backdrop of a large body of research that has paid considerable attention to the ways in which social identification is a determinant of significant organizational outcomes such as leadership, motivation, and communication. To date however, this work has devoted far less energy to questions of individuals' health and well-being in organizations. The present findings are therefore noteworthy because they suggest that social identifications in organizations are as important for individuals' health and well-being as they are for their productivity and performance. Indeed, in many ways we see these two correlates of social identifications not only to be equally important, but also to be intertwined. Moreover, it is precisely in helping us to understand the nature of this relationship between health and social endeavor that much of the value of a social identity approach resides. 


\section{Footnote}

1. Visual inspection of the forest plot indicates some outliers to the left and the right side of the summary effect that may account for considerable heterogeneity in effect sizes. Analysis excluding the three most extreme effect sizes to either side of the summary effect indicates an effect size of, $r=.21,95 \%$ CIs: $[.18, .25] ; Z=11.71$, and a heterogeneity of effect sizes across samples of, $Q(51)=269.61, p<.001, T=.111$, with a $95 \%$ prediction interval of -.01 to .42 .

2. In additional analyses, we also coded for Hofstede's culture dimensions: power distance, individualism, masculinity, uncertainty avoidance, pragmatism, and indulgence (Hofstede, 2001; Hofstede, Hofstede, \& Minkov, 2010). For van Dick and colleagues' (2007) sample which included participants from different countries, sample scores were weighted by the number of participants from a particular country. There was no evidence that the identification-health relationship was moderated by any of the culture dimensions: power distance: $b=.0004,95 \%$ CIs [-.0022, .0093], $Z=1.22$; individualism: $b=.0044,95 \%$ CIs [$.0007, .0095], Z=1.68$; masculinity: $b=-.0003,95 \%$ CIs $[-.0061, .0056], Z=.08$; uncertainty avoidance: $b=-.0008,95 \%$ CIs $[-.0037, .0020], Z=.57$; pragmatism: $b=.0004$, 95\%CIs [-.0028, .0036], $Z=.23$; or indulgence: $b=-.0007,95 \%$ CIs [-.0065, .0052], $Z=.22$.

3. If the previous moderators are added to this model (and two studies are removed due to dependent subgroups in health valence and index), the overall model combining multiple outcomes was significant, $Q(7)=34.04, p<.001, R^{2}=.641$. The beta-weights were largely similar to those revealed in previous analyses with the exceptions that health index and identification measure were not significant predictors the strength of the effect sizes in this model: $S D$ in identification $(b=-.58,95 \%$ CIs $[-.92,-.23], Z=2.43)$, mean in identification $(b=-.05,95 \%$ CIs $[-.20, .09], Z=.76)$, health valence $(b=-.10,95 \%$ CIs $[-.22, .02], Z=$ 1.66), health index $(b=.19,95 \%$ CIs $[.02, .35], Z=2.22)$, identification scale $(Q[2]=5.57, p$ 
$=.062$; note that none of the samples in this subset used the measure by van Dick et al. [2004]), and gender ( $b=-.0026,95 \%$ CIs [-.0046, -.0006$], Z=2.56)$. 


\section{References}

Abrams, D., Ando, K., \& Hinkle, S. (1998). Psychological attachment to the group: Crosscultural differences in organizational identification and subjective norms as predictors of workers' turnover intentions. Personality and Social Psychology Bulletin, 24, 1027-39.

Adler, J. M., Lodi-Smith, J., Philippe, F. L., \& Houle, I. (2016). The incremental validity of narrative identity in predicting well-being: A review of the field and recommendations for the future. Personality and Social Psychology Review, 20, 142-175.

Albert, S., \& Whetten, D. A. (1985). Organizational identity. In L. L. Cummings, \& B. M. Staw (Eds.), Research in Organizational Behavior, Vol. 7: 263-295. Greenwich, CT: JAI Press.

Alnabulsi, H., \& Drury, J. (2014). Social identification moderates the effect of crowd density on safety at the Hajj. Proceedings of the National Academy of Sciences, 111, 9091-9096.

Amiot, C. E., Terry, D. J., \& Callan, V. J. (2007). Status, equity and social identification during an intergroup merger: A longitudinal study. British Journal of Social Psychology, 46, 557-577.

Anisman, H. (2014). An introduction to stress and health. London: Sage.

Anderson, N., \& Thomas, H. D. C. (1996). Workgroup socialization. In M. A. West (Ed.), Handbook of workgroup psychology (pp. 423-450). Chichester: Wiley.

APA Publications and Communications Board Working Group on Journal Article Reporting Standards (2008). Reporting standards for research in psychology: Why do we need them? What might they be? American Psychologist, 63, 839-851.

Ashforth, B. E., \& Johnson, S. A. (2001). Which hat to wear. In M. A. Hogg \& D. J. Terry (Eds.), Social identity processes in organizational contexts (pp. 31-48). New York US: Psychology Press.

Ashforth, B. E., \& Kreiner, G. E. (1999). “How can you do it?”: Dirty work and the challenge of constructing a positive identity. Academy of Management Review, 24, 413-434. 
Ashforth, B. E., Harrison, S. H., \& Corley, K. G. (2008). Identification in organizations: An examination of four fundamental questions. Journal of Management, 34, 325-374.

Ashforth, B. E., \& Mael, F. (1989). Social identity theory and the organization. Academy of Management Review, 14, 20-39.

Ashforth, B. E., Rogers, K. M., Pratt, M. G., \& Pradies, C. (2014). Ambivalence in organizations: A multilevel approach. Organization Science, 25, 1453-1578.

Ashmore, R. D., Deaux, K., \& McLaughlin-Volpe, T. (2004). An organizing framework for collective identity: Articulation and significance of multidimensionality. Psychological Bulletin, 130, 80-114.

*Avanzi, L., Schuh, S. C., Fraccaroli, F., van Dick, R. (2015). Why does organizational identification relate to reduced employee burnout? The mediating influence of social support and collective efficacy. Work \& Stress, 29, 1-10.

*Avanzi, L., Fraccaroli, F., Sarchielli, G., Ullrich, J., \& van Dick, R. (2014). Staying or leaving: A combined social identity and social exchange approach to predicting employee turnover intentions. International Journal of Productivity and Performance Management, 63, 272-289.

*Avanzi, L., van Dick, R., Fraccaroli, F., \& Sarchielli, G. (2012). The downside of organizational identification: Relationships between identification, workaholism and well-being. Work \& Stress, 26, 289-307.

Bakker, A. B., Schaufeli, W. B., Leiter, M. P., \& Taris, T. W. (2008). Work engagement: An emerging concept in occupational health psychology. Work \& Stress, 22, 187-200.

*Barbier, M., Dardenne, B., \& Hansez, I. (2013). A longitudinal test of the Job DemandsResources model using perceived stigma and social identity. European Journal of Work and Organizational Psychology, 22, 532-546.

Barker, J., \& Tompkins, P. (1994). Identification in the self-managing organization: 
Characteristics of target and tenure. Human Communication Research, 21, 223-240.

Baumeister, R. F., \& Leary, M. R. (1995). The need to belong: Desire for interpersonal attachments as a fundamental human motivation. Psychological Bulletin, 117, 497-529.

*Bedeian, A. G. (2007). Even if the tower is "ivory," it isn't "white:" Understanding the consequences of faculty cynicism. Academy of Management Learning \& Education, 6, 9-32.

Bergami, M., \& Bagozzi, R. P. (2000). Self-categorization, affective commitment and group selfesteem as distinct aspects of social identity in the organization. British Journal of Social Psychology, 39, 555-577.

Berkman, L. F. (2001). Social ties and mental health. Journal of Urban health, 78, 458-467.

*Bizumic, B., Reynolds, K. J., Turner, J. C., Bromhead, D., \& Subasic, E. (2009). The role of the group in individual functioning: School identification and the psychological well-being of staff and students. Applied Psychology, 58, 171-192.

*Bjerregaard, K., Haslam, S. A., Morton, T. A., Ryan, M. K. (2014). The motivation of care workers: Clarifying the importance of social and relational identification. Unpublished manuscript, Psychology: College of Life and Environmental Science, University of Exeter, UK.

Blader, S. L., \& Tyler, T. R. (2009). Testing and extending the group engagement model: Linkages between social identity, procedural justice, economic outcomes, and extrarole behavior. Journal of Applied Psychology, 94, 445-464.

Blanchard, C. M., Amiot, C. E., Perreault, S., Vallerand, R. J., \& Provencher, P. (2009). Cohesiveness, coach's interpersonal style and psychological needs: Their effects on selfdetermination and athletes' subjective well-being. Psychology of Sport and Exercise, 10, 545551.

Borenstein, M., Hedges, L. V., Higgins, J. P. T., \& Rothstein, H. R. (2009). Introduction to meta- 
analysis. Hoboken, NJ: Wiley.

Branscombe, N. R., Schmitt, M. T., \& Harvey, R. D. (1999). Perceiving pervasive discrimination among African Americans: Implications for group identification and well-being. Journal of Personality and Social Psychology, 77, 135-149.

Brähler, E., Hinz, A., Scheer, J. W. (2008). GBB-24: The Giessener Symptom Checklist [GBB24: Der Giessener Beschwerdebogen]. Bern: Huber.

Brown, R., Condor, S., Mathews, A., Wade, G., \& Williams, J. (1986). Explaining intergroup differentiation in an industrial organization. Journal of Occupational Psychology, 59, 273-286.

Cacioppo, J. T., Hawkley, L. C., \& Berntson, G. G. (2003). The anatomy of loneliness. Current Directions in Psychological Science, 12, 71-74.

Cacioppo, J. T., Berntson, G. G., Sheridan, J. F., \& McClintock, M. K. (2000). Multilevel integrative analyses of human behavior: Social neuroscience and the complementing nature of social and biological approaches. Psychological Bulletin, 126, 829-843.

Cameron, J. E. (2004). A three-factor model of social identity. Self and identity, 3, 239-262.

Campbell, D. T. (1958). Common fate, similarity, and other indices of the status of aggregates of persons as social entities. Behavioral Science, 3, 14-25.

Cantor, N., Kemmelmeier, M., Basten, J., \& Prentice, D. A. (2002). Life task pursuit in social groups: Balancing self-exploration and social integration. Self \& Identity, 1, 177-184.

Carron, A. V., \& Spink, K. S. (1995). The group size-cohesion relationship in minimal groups. Small Group Research, 26, 86-105.

*Christ, O. (2004). An examination of the transactional stress theory in teachers in training [Die Überprüfung der transaktionalen Stresstheorie im Lehramtsreferendariat]. Unpublished raw data, Department of Psychology, Goethe University Frankfurt, Germany.

*Cicero, L., Pierro, A., \& van Knippenberg, D. (2007). Leader group prototypicality and job 
satisfaction: The moderating role of job stress and team identification. Group Dynamics:

Theory, Research, and Practice, 11, 165-175.

Cohen, S. (2004). Social relationships and health. American Psychologist, 59, 676.

Cohen, S., Doyle, W. J., Skoner, D. P., Rabin, B. S., \& Gwaltney, J. M. (1997). Social ties and susceptibility to the common cold. JAMA, 277, 1940-1944.

Cohen, S., Kamarck, T., \& Mermelstein, R. (1983). A global measure of perceived stress. Journal of Health and Social Behavior, 24, 385-396.

Cooper, H. M. (1998). Synthesizing research: A guide for literature reviews (3rd ed.). Thousand Oaks, CA: Sage.

Cooper, H., Robinson, J. C., \& Patall, E. A. (2006). Does homework improve academic achievement? A synthesis of research, 1987-2003. Review of Educational Research, 76, 1-62.

Crabtree, J. W., Haslam, S. A., Postmes, T., \& Haslam, C. (2010). Mental health support groups, stigma, and self-esteem: Positive and negative implications of group identification. Journal of Social Issues, 66, 553-569.

Cruwys, T., Dingle, G. A., Haslam, C., Haslam, S. A., Jetten, J., \& Morton, T. A. (2013). Social group memberships protect against future depression, alleviate depression symptoms and prevent depression relapse. Social Science \& Medicine, 98, 179-186.

Cruwys, T., Haslam, S. A., Dingle, G. A., Haslam, C., \& Jetten, J. (2014). Depression and social identity: An integrative review. Personality and Social Psychology Review, 18, 215-238.

Cruwys, T., South, E. I., Greenaway, K. H., \& Haslam, S. A. (2015). Social identity reduces depression by fostering positive attributions. Social Psychological and Personality Science, 6, $65-74$.

Cumming, G. (2014). The new statistics: Why and how. Psychological Science, 25, 7-29. 
*Das, D., Dharwadkar, R., \& Brandes, P. (2008). The importance of being 'Indian': Identity centrality and work outcomes in an off-shored call center in India. Human Relations, 61, 1499-1530.

Diener, E. (2000). Subjective well-being: The science of happiness and a proposal for a national index. American Psychologist, 55, 34-43.

Diener, E., \& Biswas-Diener, R. (2008). Happiness: Unlocking the mysteries of psychological wealth. Malden US: Blackwell.

Doosje, B., Ellemers, N., \& Spears, R. (1995). Perceived intragroup variability as a function of group status and identification. Journal of Experimental Social Psychology, 31, 410-436.

Drury, J. (2012). Collective resilience in mass emergencies and disasters. In J. Jetten, C. Haslam, \& S. A. Haslam (Eds.), The Social Cure: Identity, Health and Well-being (pp. 195-215). New York: Psychology Press.

Drury, J., Cocking, C., \& Reicher, S. (2009). Everyone for themselves? A comparative study of crowd solidarity among emergency survivors. British Journal of Social Psychology, 48, 487506.

Dutton, J. E., Dukerich, J. M., \& Harquail, C. V. (1994). Organizational images and member identification. Administrative Science Quarterly, 39, 239-263.

Duval, S., \& Tweedie, R. (2000). Trim and fill: A simple funnel-plot-based method of testing and adjusting for publication bias in meta-analysis. Biometrics, 56, 455-463.

Egger, M., Juni, P., Bartlett, C., Holenstein, F., \& Sterne, J. (2003). How important are comprehensive literature searches and the assessment of trial quality in systematic reviews? Empirical study. Health Technology Assessment, 7, 1-76.

Egger, M., Smith, G. D., Schneider, M., \& Minder, C. (1997). Bias in meta-analysis detected by a simple, graphical test. British Medical Journal, 315, 629-634. 
Ellemers, N. (1993). The influence of socio-structural variables on identity management strategies. European Review of Social Psychology, 4, 27-57.

Ellemers, N. (2012). The group self. Science, 336, 848-852.

Ellemers, N., De Gilder, D., \& Haslam, S. A. (2004). Motivating individuals and groups at work: A social identity perspective on leadership and group performance. Academy of Management Review, 29, 459-478.

Ellemers, N., Kortekaas, P., \& Ouwerkerk, J. W. (1999). Self-categorisation, commitment to the group and group self-esteem as related but distinct aspects of social identity. European Journal of Social Psychology, 29, 371-389.

Escartín, J., Ullrich, J., Zapf, D., Schlüter, E., \& van Dick, R. (2013). Individual-and group-level effects of social identification on workplace bullying. European Journal of Work and Organizational Psychology, 22, 182-193.

Eschleman, K. J., Bowling, N. A., \& Alarcon, G. M. (2010). A meta-analytic examination of hardiness. International Journal of Stress Management, 17, 277-307.

*Fampri, R. (2003). Does questionnaire framing affect levels of self-reported organizational identification and burnout? Unpublished raw data, Psychology: College of Life and Environmental Science, University of Exeter, UK.

Ferguson, C. J., \& Brannick, M. T. (2012). Publication bias in psychological science: Prevalence, methods for identifying and controlling, and implications for the use of metaanalyses. Psychological Methods, 17, 120.

Fishbein, M., \& Ajzen, I. (1974). Attitudes towards objects as predictors of single and multiple behavioral criteria. Psychological Review, 81, 29-74.

*Frisch, J. U., Häusser, J. A., van Dick, R., \& Mojzisch, A. (2014). Making support work: The 
interplay between social support and social identity. Journal of Experimental Social Psychology, 55, 154-161.

Gallo, L. C., \& Matthews, K. A. (2003). Understanding the association between socioeconomic status and physical health: Do negative emotions play a role? Psychological Bulletin, 129, 1051.

*Galang, M., \& Jones, S. E. (2014). Workplace bullying and job satisfaction: The mediating role of social identity. Unpublished Manuscript, Oxford Brookes University, UK.

Gallagher, S., Meaney, S., \& Muldoon, O. T. (2014). Social identity influences stress appraisals and cardiovascular reactions to acute stress exposure. British Journal of Health Psychology. $19,566-579$.

Gleibs, I. H., Haslam, C., Jones, J. M., Haslam, S. A., McNeill, J., \& Connolly, H. (2011). No country for old men? The role of a 'Gentlemen's Club' in promoting social engagement and psychological well-being in residential care. Aging and Mental Health, 15, 456-466.

Golden, L., \& Wiens-Tuers, B. (2006). To your happiness? Extra hours of labor supply and worker well-being. The Journal of Socio-Economics, 35, 382-397

Goldberg, D. P. (1972). The detection of psychiatric illness by questionnaire. London: Oxford University Press.

Graeser, S. (2011). Salutogenic factors for mental health promotion in work settings and organizations. International Review of Psychiatry, 23, 508-515.

Greenaway, K., Haslam, S. A., Branscombe, N. R., Cruwys, T., Ysseldyk, R., \& Heldreth, C. (2015). From "we" to "me": Group identification enhances perceived personal control with consequences for health and well-being. Journal of Personality and Social Psychology, 1, 5374.

Griffith, J. (2002). Multilevel analysis of cohesion's relation to stress, well-being, identification, 
disintegration, and perceived combat readiness. Military Psychology, 14, 217-239.

Grossman, P., Niemann, L., Schmidt, S., \& Walach, H. (2004). Mindfulness-based stress reduction and health benefits: A meta-analysis. Journal of Psychosomatic Research, 57, 3543.

*Grubba, C., Ahlswede, O. (2002). Relationships between job satisfaction, team climate, identification, and engagement in the banking sector [Zusammenhänge zwischen Arbeitszufriedenheit, Teamklima, Identifikation und Engangement im Bankenbereich]. Unpublished raw data, Department of Psychology, Goethe University Frankfurt, Germany.

Hamilton, D. L., \& Sherman, S. J. (1996). Perceiving persons and groups. Psychological Review, 103, 336-355.

*Harris, G. E., \& Cameron, J. E. (2005). Multiple dimensions of organizational identification and commitment as predictors of turnover intentions and psychological well-being. Canadian Journal of Behavioural Science, 37, 159-169.

Harrison, D. A., \& Klein, K. J. (2007). What's the difference? Diversity constructs as separation, variety, or disparity in organizations. Academy of Management Review, 32, 1199-1228.

Haslam, C., Holme, A., Haslam, S. A., Iyer, A., Jetten, J., \& Williams, W. H. (2008). Maintaining group memberships: Social identity continuity predicts well-being after stroke. Neuropsychological Rehabilitation, 18, 671-691.

Haslam, S. A. (1997). Stereotyping and social influence: Foundations of stereotype consensus. In: R. Spears, P. J. Oakes, N. Ellemers \& S. A. Haslam (Eds.), The social psychology of stereotyping and group life (pp. 119-143). Oxford, UK: Blackwell.

Haslam, S. A. (2001). Psychology in organizations: The social identity approach. London \& Thousands Oaks, CA US: Sage.

Haslam, S. A. (2014). Making good theory practical: Five lessons for an Applied Social Identity 
Approach to challenges of organizational, health, and clinical psychology. British Journal of Social Psychology, 53, 1-20.

Haslam, S. A., Eggins, R. A., \& Reynolds, K. J. (2003). The ASPIRe model: Actualizing Social and Personal Identity Resources to enhance organizational outcomes. Journal of Occupational and Organizational Psychology, 76, 83-113.

Haslam, S. A., Jetten, J., Postmes, T., \& Haslam, C. (2009). Social identity, health and wellbeing: An emerging agenda for applied psychology. Applied Psychology: An International Review, 58, 1-23.

*Haslam, S. A., Jetten, J., \& Waghorn, C. (2009). Social identification, stress and citizenship in teams: A five-phase longitudinal study. Stress and Health, 25, 21-30.

*Haslam, S. A., O'Brien, A., Jetten, J., Vormedal, K., \& Penna, S. (2005). Taking the strain: Social identity, social support, and the experience of stress. British Journal of Social Psychology, 44, 355-370.

*Haslam, S. A., \& Reicher, S. (2006). Stressing the group: Social identity and the unfolding dynamics of responses to stress. Journal of Applied Psychology, 91, 1037-1052.

Haslam, S. A., Reicher, S. D., \& Platow, M. J. (2011). The new psychology of leadership: Identity, influence and power. London \& New York: Psychology Press.

*Häusser, J. A., Kattenstroth, M., van Dick, R., \& Mojzisch, A. (2012). "We” are not stressed: Social identity in groups buffers neuroendocrine stress reactions. Journal of Experimental Social Psychology, 48, 973-977.

Hedges, L. V., \& Olkin, I. (1985). Statistical methods for meta-analysis. Orlando, FL: Academic Press.

Helliwell, J. F., \& Putnam, R. D. (2004). The social context of well-being. Philosophical Transactions of the Royal Society London, Biological Sciences, 359, 1435-1446. 
Helliwell, J. F., Layard, R., \& Sachs, J. (eds.) (2013). World Happiness Report 2013. New York: UN Sustainable Development Solutions Network.

*Herrbach, O. (2006). A matter of feeling? The affective tone of organizational commitment and identification. Journal of Organizational Behavior, 27, 629-643.

Higgins, J., Thompson, S. G., \& Spiegelhalter, D. J. (2009). A re-evaluation of random-effects meta-analysis. Journal of the Royal Statistical Society: Series A (Statistics in Society), 172, 137-159.

Hofstede, G. (2001). Culture's consequences: Comparing values, behaviors, institutions, and organizations across nations (2nd Edition). Thousand Oaks CA: Sage Publications.

Hofstede, G., Hofstede, G. J., \& Minkov, M. (2010). Culture and organizations, Software of the mind: Intercultural cooperation and its importance for survival (3rd Ed). New York: McGraw Hill.

Hogg, M. A., Abrams, D. (1988). Social Identifications: A social psychology of intergroup relations and group processes. London \& New York: Routledge.

Hogg, M. A., \& Terry, D. J. (Eds.) (2001). Social identity processes in organizational contexts. Philadelphia, Hove \& PA US: Psychology Press.

Holt-Lunstad, J., Smith, T. B., \& Layton, J. B. (2010). Social relationships and mortality risk: A meta-analytic review. PLoS Medicine, 7, e1000316.

Hopkins, N., \& Reicher, S. (2016). The psychology of health and well-being in mass gatherings: A review and a research agenda. Journal of Epidemiology and Global Health, 6, 49-57.

Hornsey, M. J., \& Hogg, M. A. (2000). Assimilation and diversity: An integrative model of subgroup relations. Personality and Social Psychology Review, 4, 143-156.

*Horton, K. E., McClelland, C. R., \& Griffin, M. A. (2014). Defined by our hierarchy? How hierarchical positions shape our identifications and well-being at work. Human Relations, 67, 
1167-1188.

Howell, J. L., Koudenburg, N., Loschelder, D. D., Weston, D., Fransen, K., De Dominicis, S., ... \& Haslam, S. A. (2014). Happy but unhealthy: The relationship between social ties and health in an emerging network. European Journal of Social Psychology, 44, 612-621.

Hunter, J. E., \& Schmidt, F. L. (2000). Fixed effects vs. random effects meta-analysis models: Implications for cumulative research knowledge. International Journal of Selection and Assessment, 8, 275-292.

Inglehart, R., \& Baker, W. E. (2000). Modernization, cultural change, and the persistence of traditional values. American Sociological Review, 65, 19-51.

*Ishii, K. (2012). Dual organizational identification among Japanese expatriates: The role of communication in cultivating subsidiary identification and outcomes. The International Journal of Human Resource Management, 23, 1113-1128.

Iyer, A., Jetten, J., Tsivrikos, D., Postmes, T., \& Haslam, S. A. (2009). The more (and the more compatible) the merrier: Multiple group memberships and identity compatibility as predictors of adjustment after life transitions. British Journal of Social Psychology, 48, 707-733.

Jackson, J. W. (2002). Intergroup attitudes as a function of different dimensions of group identification and perceived intergroup conflict. Self and Identity, 1, 11-33.

Jans, L., Leach, C. W., Garcia, R. L., \& Postmes, T. (2015). The development of group influence on in-group identification: A multilevel approach. Group Processes \& Intergroup Relations, $18,190-209$.

Jans, L., Postmes, T., \& Van der Zee, K. I. (2011). The induction of shared identity: The positive role of individual distinctiveness for groups. Personality and Social Psychology Bulletin, 37 , 1130-1141.

Jetten, J., Branscombe, N. R., Schmitt, M. T., \& Spears, R. (2001). Rebels with a cause: Group 
identification as a response to perceived discrimination from the mainstream. Personality and Social Psychology Bulletin, 27, 1204-1213.

Jetten, J., Haslam, C., \& Haslam, S. A. (Eds.) (2012). The social cure: Identity, health and wellbeing. New York, NY US: Psychology Press.

Jetten, J., Haslam, C., Haslam, S. A., Dingle, G., \& Jones, J. M. (2014). How groups affect our health and well-being: The path from theory to policy. Social Issues and Policy Review, 8, 103-130.

*Jimmieson, N. L., McKimmie, B. M., Hannam, R. L., \& Gallagher, J. (2010). An investigation of the stress-buffering effects of social support in the occupational stress process as a function of team identification. Group Dynamics: Theory, Research, and Practice, 14, 350-367.

Karasawa, M. (1991). Toward an assessment of social identity: The structure of group identification and its effects on in-group evaluations. British Journal of Social Psychology, 30, 293-307.

Kepes, S., Banks, G. C., McDaniel, M., \& Whetzel, D. L. (2012). Publication bias in the organizational sciences. Organizational Research Methods, 15, 624-662.

Kendler, K. S., Myers, J., \& Prescott, C. A. (2005). Sex differences in the relationship between social support and risk for major depression: a longitudinal study of opposite-sex twin pairs. American Journal of Psychiatry, 162, 250-256.

*Knight, C., \& Haslam, S. A. (2010a). Your place or mine? Organizational identification and comfort as mediators of relationships between the managerial control of workspace and employees' satisfaction and well-being. British Journal of Management, 21, 717-735.

*Knight, C., \& Haslam, S. A. (2010b). The relative merits of lean, enriched, and empowered offices: An experimental examination of the impact of workspace management strategies on well-being and productivity. Journal of Experimental Psychology: Applied, 16, 158. 
*Knowles, M., \& Smith, L. G. E. (2013). Occupational stress and perceived job performance: The moderating role of team identification. Unpublished Manuscript, University of Bath, UK.

*Kreiner, G. E., \& Ashforth, B. E. (2004). Evidence toward an expanded model of organizational identification. Journal of Organizational Behavior, 25, 1-27.

Lambert, P. S., \& Prandy, K. (2014) CAMSIS project webpages: Cambridge Social Interaction and Stratification Scales, Retrieved 15 January 2015 from http://www.camsis.stir.ac.uk/ .

Lazarus, R. S., \& Folkman, S. (1984). Stress, appraisal, and coping. New York: Springer.

Leach, C. W., van Zomeren, M., Zebel, S., Vliek, M. L., Pennekamp, S. F., Doosje, B., ... \& Spears, R. (2008). Group-level self-definition and self-investment: a hierarchical (multicomponent) model of in-group identification. Journal of Personality and Social Psychology, 95, 144-165.

Leary, M. R. (1990). Responses to social exclusion: Social anxiety, jealousy, loneliness, depression, and low self-esteem. Journal of Social and Clinical Psychology, 9, 221-229.

Lee, R. T., \& Ashforth, B. E. (1996). A meta-analytic examination of the correlates of the three dimensions of job burnout. Journal of Applied Psychology, 81, 123-133.

Levine, M., Cassidy, C., Brazier, G., \& Reicher, S. D. (2002). Self-categorization and bystander non-intervention: Two experimental studies. Journal of Applied Social Psychology, 32, 14521463.

Levine, M., Prosser, A., Evans, D., \& Reicher, S. D. (2005). Identity and emergency intervention: How social group membership and inclusiveness of group boundaries shape helping behavior. Personality and Social Psychology Bulletin, 31, 443-453.

Levine, R. M., \& Reicher, S. D. (1996). Making sense of symptoms: Self-categorization and the meaning of illness and injury. British Journal of Social Psychology, 35, 245-256.

Lickel, B., Hamilton, D. L., Wieczorkowska, G., Lewis, A., Sherman, S. J., \& Uhles, A. N. 
(2000). Varieties of groups and the perception of group entitativity. Journal of Personality and Social Psychology, 78, 223-246.

Liao, H., Liu, D., \& Loi, R. (2010). Looking at both sides of the social exchange coin: A social cognitive perspective on the joint effects of relationship quality and differentiation on creativity. Academy of Management Journal, 53, 1090-1109.

Lindström, B., \& Eriksson, M. (2006). Contextualizing salutogenesis and Antonovsky in public health development. Health Promotion International, 21, 238-244.

Lipsey, M. W., \& Wilson, D. B. (2001). Practical meta-analysis. London, England: Sage.

Lundberg, U., \& Cooper, C. L. (2011). The science of occupational health: stress, psychobiology, and the new world of work. Oxford, UK: John Wiley \& Sons.

Luhtanen, R., \& Crocker, J. (1992). A collective self-esteem scale: Self-evaluation of one's social identity. Personality and Social Psychology Bulletin, 18, 302-318.

Lyubomirsky, S., King, L., \& Diener, E. (2005). The benefits of frequent positive affect: Does happiness lead to success? Psychological Bulletin, 131, 803-855.

MacDonald, G., \& Leary, M. R. (2005). Why does social exclusion hurt? The relationship between social and physical pain. Psychological Bulletin, 131, 202-223.

Mael, F., \& Ashforth, B. E. (1992). Alumni and their alma mater: A partial test of the reformulated model of organizational identification. Journal of Organizational Behavior, 13, 103-123.

Mael, F. A., \& Tetrick, L. E. (1992). Identifying organizational identification. Educational and Psychological Measurement, 52, 813-824.

Markus, H. R., \& Kitayama, S. (1994). A collective fear of the collective: Implications for selves and theories of selves. Personality and Social Psychology Bulletin, 20, 568-579.

Maslach, C., \& Jackson, S. E. (1981). The measurement of experienced burnout. Journal of 
Organizational Behavior, 2, 99-113.

Maslach, C., Schaufeli, W. B., \& Leiter, M. P. (2001). Job burnout. Annual Review of Psychology, 52, 397-422.

*Matheson, K., \& Cole, B. M. (2004). Coping with a threatened group identity: Psychosocial and neuroendocrine responses. Journal of Experimental Social Psychology, 40, 777-786.

McAuley, L., Tugwell, P., \& Moher, D. (2000). Does the inclusion of grey literature influence estimates of intervention effectiveness reported in meta-analyses? The Lancet, 356, 12281231.

*Menzel, B. (2007). Work motivation and identification in nurses [Arbetismotivation und Identifikation bei Krankenpflegepersonal]. Unpublished raw data, Department of Psychology, Goethe University Frankfurt, Germany.

*Merecz, D., \& Andysz, A. (2012). Relationship between Person-Organization fit and objective and subjective health status (Person-Organization fit and health). International Journal of Occupational Medicine and Environmental Health, 25, 166-177.

Mesmer-Magnus, J., Glew, D. J., \& Viswesvaran, C. (2012). A meta-analysis of positive humor in the workplace. Journal of Managerial Psychology, 27, 155-190.

Meyer, J. P., Becker, T. E., \& van Dick, R. (2006). Social identities and commitments at work: Toward an integrative model. Journal of Organizational Behavior, 27, 665-683.

*Mishra, S. K. (2013). Perceived external prestige and employee outcomes: Mediation effect of organizational identification. Corporate Reputation Review, 16, 220-233.

*Mishra, S. K., \& Bhatnagar, D. (2010). Linking emotional dissonance and organizational identification to turnover intention and emotional well-being: A study of medical representatives in India. Human Resource Management, 49, 401-419.

Moreland, R. L., \& Levine, J. M. (2001). Socialization in organizations and workgroups. In M. E. 
Turner (Ed.), Groups at work: theory and research (pp. 69-112). Hillsdale, NJ: Erlbaum.

Muldoon, O. T., \& Downes, C. (2007). Social identification and post-traumatic stress symptoms in post-conflict Northern Ireland. The British Journal of Psychiatry, 191, 146-149.

Mühlhaus, J. \& Bouwmeester, O. (2016). The paradoxical effect of self-categorization on work stress in a high-status occupation: Insights from management consulting. Human Relations. Advance online publication. Doi:10.1177/0018726715626255.

$\mathrm{Ng}, \mathrm{T}$. W. (2015). The incremental validity of organizational commitment, organizational trust, and organizational identification. Journal of Vocational Behavior, 88, 154-163.

Ng, T. W., \& Feldman, D. C. (2008). Long work hours: a social identity perspective on metaanalysis data. Journal of Organizational Behavior, 29, 853-880.

*Nieuwenhuis, M., Knight, C., Postmes, T., \& Haslam, S. A. (2014). The relative benefits of green versus lean office space: Three field experiments. Journal of Experimental Psychology: Applied, 20, 199-214.

*O'Brien, A. T., \& Haslam, S. A. (2004). Shaping the future: The 2003 Stress Survey of Staff in the West Dorset General Hospitals Trust. Psychology: College of Life and Environmental Science, University of Exeter, UK.

Orwin, R. G. (1983). A fail-safe N for effect size in meta-analysis. Journal of Educational Statistics, 8, 157-159.

Oyserman, D., Fryberg, S. A., \& Yoder, N. (2007). Identity-based motivation and health. Journal of Personality and Social Psychology, 93, 1011-1027.

Pandey, K., Stevenson, C., Shankar, S., Hopkins, N. P., \& Reicher, S. D. (2014). Cold comfort at the Magh Mela: Social identity processes and physical hardship. British Journal of Social Psychology, 53, 675-690. 
Parker, S. K. (2014). Beyond motivation: Job and work design for development, health, ambidexterity, and more. Annual Review of Psychology, 65, 661-691.

Parker, D. F., \& DeCotiis, T. A. (1983). Organizational determinants of job stress. Organizational Behavior and Human Performance, 32, 160-177.

Pascoe, E. A., \& Smart Richman, L. (2009). Perceived discrimination and health: A metaanalytic review. Psychological Bulletin, 135, 531-554.

Patchen, M. (1970). Participation, achievement and involvement on the job. Englewood Cliffs NJ: Prentice-Hall.

Perkins, H. W., \& Wechsler, H. (1996). Variation in perceived college drinking norms and its impact on alcohol abuse: A nationwide study. Journal of Drug Issues, 26, 961-974.

Peters, K., Ryan, M. K., Haslam, S. A., \& Fernandes, H. (2012). To belong or not to belong: Evidence that women's occupational disidentification is promoted by lack of fit with masculine occupational prototypes. Journal of Personnel Psychology, 11, 148-158.

Phinney, J. S. (1992). The multigroup ethnic identity measure a new scale for use with diverse groups. Journal of Adolescent Research, 7, 156-176.

*Pisarski, A., Lawrence, S. A., Bohle, P., \& Brook, C. (2008). Organizational influences on the work life conflict and health of shiftworkers. Applied Ergonomics, 39, 580-588.

Platow, M. J., Voudouris, N. J., Gilford, N., Jamieson, R., Najdovski, L., Papaleo, N., ... \& Terry, L. (2007). In-group reassurance in a pain setting produces lower levels of physiological arousal: Direct support for a self-categorization analysis of social influence. European Journal of Social Psychology, 37, 649-660.

Podsakoff, P. M., MacKenzie, S. B., Lee, J., \& Podsakoff, N. P. (2003). Common method biases in behavioral research: A critical review of the literature and recommended remedies. Journal of Applied Psychology, 88, 879-903. 
*Portaluri, S. (2013). Work and well-being: A two-wave study exploring the relationship between leadership effectiveness, social identity, psychological well-being and job involvement. Unpublished Manuscript, Australian National University, Australia.

Postmes, T., \& Branscombe, N. R. (2002). Influence of long-term racial environmental composition on subjective well-being in African Americans. Journal of Personality and Social Psychology, 83, 735-751.

Postmes, T., \& Branscombe, N. R. (2010). Rediscovering social identity. New York: Psychology Press.

Postmes, T., Haslam, S. A., \& Jans, L. (2013). A single-item measure of social identification: Reliability, validity, and utility. British Journal of Social Psychology, 52, 597-617.

Prandy, K. (1990). The revised Cambridge scale of occupations. Sociology, 24, 629-655.

Pratt, M. G. (2000). The good, the bad, and the ambivalent: Managing identification among Amway distributors. Administrative Science Quarterly, 45, 456-493.

Ramarajan, L. (2014). Past, present and future research on multiple identities: Toward an intrapersonal network approach. The Academy of Management Annals, 8, 589-659.

Ramarajan, L., \& Reid, E. (2013). Shattering the myth of separate worlds: Negotiating nonwork identities at work. Academy of Management Review, 38, 621-644.

Reicher, S. D., Cassidy, C., Wolpert. I., Hopkins, N. \& Levine, M. (2006). Saving Bulgaria’s Jews: An analysis of social identity and the mobilisation of social solidarity. European Journal of Social Psychology, 36, 49-72.

Reicher, S. D., \& Haslam, S. A., (2006). On the agency of individuals and groups: Lessons from the BBC Prison Study. In: T. Postmes \& J. Jetten (Eds.), Individuality and the group: Advances in social identity (pp.237-257). London: Sage. 
Reicher, S. D., Spears, R., \& Haslam, S. A. (2010). The social identity approach in social psychology. In M. S. Wetherell \& C. T. Mohanty (Eds.), Sage Identities Handbook (pp. 4562). London: Sage.

Richardson, K. M., \& Rothstein, H. R. (2008). Effects of occupational stress management intervention programs: A meta-analysis. Journal of Occupational Health Psychology, 13, 6993.

Riketta, M. (2005). Organizational identification: A meta-analysis. Journal of Vocational Behavior, 66, 358-384.

Riketta, M., \& van Dick, R. (2005). Foci of attachment in organizations: A meta-analytic comparison of the strength and correlates of workgroup versus organizational identification and commitment. Journal of Vocational Behavior, 67, 490-510.

Roccas, S., Sagiv, L., Schwartz, S., Halevy, N., \& Eidelson, R. (2008). Toward a unifying model of identification with groups: Integrating theoretical perspectives. Personality and Social Psychology Review, 12, 280-306.

Ryan, R. M., \& Deci, E. L. (2000). Self-determination theory and the facilitation of intrinsic motivation, social development, and well-being. American Psychologist, 55, 68-78.

Ryff, C. D., \& Singer, B. (1998). The contours of positive human health. Psychological Inquiry, 9, 1-28.

Sacker, A., Firth, D., Fitzpatrick, R., Lynch, K., \& Bartley, M. (2000). Comparing health inequality in men and women: Prospective study of mortality 1986-96. British Medical Journal, 320, 1303-1307.

Sani, F. (Ed.). (2008). Self continuity: Individual and collective perspectives. New York, NY US: Psychology Press. 
Sani, F., Bowe, M., \& Herrera, M. (2008). Perceived collective continuity and social well-being: Exploring the connections. European Journal of Social Psychology, 38, 365-374.

*Sani, F., Herrera, M., Wakefield, J. R., Boroch, O., \& Gulyas, C. (2012). Comparing social contact and group identification as predictors of mental health. British Journal of Social Psychology, 51, 781-790.

*Sani, F., Magrin, M. E., Scrignaro, M., \& McCollum, R. (2010). In-group identification mediates the effects of subjective in-group status on mental health. British Journal of Social Psychology, 49, 883-893.

Schaufeli, W. B., Salanova, M., González-Romá, V., \& Bakker, A. B. (2002). The measurement of engagement and burnout: A two sample confirmatory factor analytic approach. Journal of Happiness Studies, 3, 71-92.

Scheier, M. F., \& Carver, C. S. (1992). Effects of optimism on psychological and physical wellbeing: Theoretical overview and empirical update. Cognitive Therapy and Research, 16, 201228.

Schmitt, M. T., Branscombe, N. R., Postmes, T., \& Garcia, A. (2014). The consequences of perceived discrimination for psychological well-being: A meta-analytic review. Psychological Bulletin, 140, 921-948.

Seligman, M. E., \& Csikszentmihalyi, M. (2000). Positive psychology: An introduction. American Psychologist, 55, 5-14.

Sellers, R. M., Smith, M. A., Shelton, J. N., Rowley, S. A., \& Chavous, T. M. (1998). Multidimensional model of racial identity: A reconceptualization of African American racial identity. Personality and Social Psychology Review, 2, 18-39.

Shamir, B., \& Kark, R. (2004). A single-item graphic scale for the measurement of organizational 
identification. Journal of Occupational and Organizational Psychology, 77, 115-123.

Sheldon, K. M., \& Bettencourt, B. (2002). Psychological need-satisfaction and subjective wellbeing within social groups. British Journal of Social Psychology, 41, 25-38.

Sherman, D. K., Kinias, Z., Major, B., Kim, H. S., \& Prenovost, M. (2007). The group as a resource: Reducing biased attributions for group success and failure via group affirmation. Personality and Social Psychology Bulletin, 33, 1100-1112.

Simonsohn, U., Nelson, L. D., \& Simmons, J. P. (2014). P-curve: A key to the filedrawer. Journal of Experimental Psychology: General, 143, 534-547.

Simonsohn, U., Simmons, J. P., \& Nelson, L. D. (2015). Better P-curves: Making P-curve analysis more robust to errors, fraud, and ambitious P-hacking, a Reply to Ulrich and Miller (2015). Journal of Experimental Psychology: General, 144, 1146-1152.

Singh, J., Goolsby, J. R., \& Rhoads, G. K. (1994). Behavioral and psychological consequences of boundary spanning burnout for customer service representatives. Journal of Marketing Research, 31, 558-569.

Steffens, N. K., Haslam, S. A., Reicher, S. D., Platow, M. J., Fransen, K., Yang, J., Jetten, J., Ryan, M. K., Peters, K., \& Boen, F. (2014). Leadership as social identity management: Introducing the Identity Leadership Inventory (ILI) to assess and validate a four-dimensional model. The Leadership Quarterly, 25, 1001-1024.

Steffens, N. K., Shemla, M., Wegge, J., \& Diestel, S. (2014). Organizational tenure and employee performance: A multilevel analysis. Group \& Organization Management, 39, 664690.

*Steffens, N. K., Yang, J., Jetten, J., Haslam, S. A., \& Lipponen, J. (2014). Leader identity entrepreneurship and employee health: Lagged effects on well-being and turnover intentions. 
Unpublished Manuscript, The University of Queensland, Australia.

Stott, C., \& Drury, J. (2000). Crowds, context and identity: Dynamic categorization processes in the 'poll tax riot'. Human Relations, 53, 247-273.

*Suh, T., Houston, M. B., Barney, S. M., \& Kwon, I. W. G. (2011). The impact of mission fulfillment on the internal audience: Psychological job outcomes in a services setting. Journal of Service Research, 14, 76-92.

Tajfel, H. (1981). Social stereotypes and social groups. In J. C. Turner \& H. Giles (Eds.), Intergroup behaviour (pp.144-167). Oxford: Blackwell.

Tajfel, H., \& Turner, J. C. (1979). An integrative theory of intergroup conflict. In W. G. Austin \& S. Worchel (Eds). The social psychology of intergroup relations. Brooks / Cole.

Tanis, M., \& Postmes, T. (2005). A social identity approach to trust: Interpersonal perception, group membership and trusting behaviour. European Journal of Social Psychology, 35, 413424.

Tarrant, M., Haggar, M. S., \& Farrow, C. V. (2012). Promoting positive orientation towards health through social identity. In J. Jetten, C. Haslam, \& S. A. Haslam (Eds.), The Social Cure: Identity, Health and Well-being (pp. 39-54). New York: Psychology Press.

Taylor, S. E., \& Brown, J. D. (1988). Illusion and well-being: A social psychological perspective on mental health. Psychological Bulletin, 103, 193-210.

Thoits, P. A. (1986). Social support as coping assistance. Journal of Consulting and Clinical Psychology, 54, 416-423.

Thoits, P. A. (1994). Stressors and problem-solving: The individual as psychological activist. Journal of Health and Social Behavior, 35, 143-160.

Thoits, P. A. (1995). Stress, coping, and social support processes: Where are we? What next? Journal of Health and Social Behavior, 35, 53-79. 
*Topa, G., \& Moriano, J. A. (2013). Stress and nurses' horizontal mobbing: Moderating effects of group identity and group support. Nursing Outlook, 61, e25-e31.

Turner, J. C. (1982). Towards a redefinition of the social group. In H. Tajfel (Ed.), Social Identity and Intergroup Relations (pp. 15-40). Cambridge: Cambridge University Press.

Turner, J. C. (1991). Social influence. Milton Keynes: Open University Press.

Turner, J. C., Hogg, M. A., Oakes, P. J., Reicher, S. D., \& Wetherell, M. S. (1987).

Rediscovering the social group: A self-categorization theory. Cambridge, MA, US: Basil Blackwell.

Turner, J. C., Oakes, P. J., Haslam, S. A., \& McGarty, C. (1994). Self and collective: Cognition and social context. Personality and Social Psychology Bulletin, 20, 454-463.

Turner, J. C., \& Reynolds, K. J. (2001). The social identity perspective in intergroup relations: Theories, themes and controversies. In R. Brown \& S. Gaertner (Eds.), Handbook of social psychology: Intergroup processes (Vol. 4). Oxford, UK and Cambridge, USA: Blackwell Tyler, T. R., \& Blader, S. L. (2003). The group engagement model: Procedural justice, social identity, and cooperative behavior. Personality and Social Psychology Review, 7, 349-361.

Uchino, B. N. (2009). Understanding the links between social support and physical health: A lifespan perspective with emphasis on the separability of perceived and received support. Perspectives on Psychological Science, 4, 236-255.

Uchino, B. N., Cacioppo, J. T., \& Kiecolt-Glaser, J. K. (1996). The relationship between social support and physiological processes: A review with emphasis on underlying mechanisms and implications for health. Psychological Bulletin, 119, 488-531.

van Dick, R. (2004). My job is my castle: Identification in organizational contexts. International Review of Industrial and Organizational Psychology, 19, 171-204.

van Dick, R., \& Haslam, S. A. (2012). Stress and well-being in the workplace: Support for key 
propositions from the social identity approach. In J. Jetten, C. Haslam, \& S. A. Haslam (Eds.), The social cure: Identity, health and well-being (pp. 175-194). New York, NY US: Psychology Press.

*van Dick, R., Stierle, C., Govaris, H., Tissington, P. A., Kodakos, A. (2007). School teachers' well-being and job satisfaction: An analysis across countries and levels of explanation. In J. Löwstedt, P. Larsson, S. Karsten, \& R. van Dick (Eds). From Intensified work to professional development. Brussels (BE): PIE Peter Lang.

van Dick, R., van Knippenberg, D., Kerschreiter, R., Hertel, G., \& Wieseke, J. (2008). Interactive effects of work group and organizational identification on job satisfaction and extra-role behavior. Journal of Vocational Behavior, 72, 388-399.

*van Dick, R., \& Wagner, U. (2002). Social identification among school teachers: Dimensions, foci, and correlates. European Journal of Work and Organizational Psychology, 11, 129-149.

*van Dick, R., Wagner, U., \& Lemmer, G. (2004). Research note: The winds of changeMultiple identifications in the case of organizational mergers. European Journal of Work and Organizational Psychology, 13, 121-138.

*van Dick, R., Wagner, U., Stellmacher, J., \& Christ, O. (2004). The utility of a broader conceptualization of organizational identification: Which aspects really matter? Journal of Occupational and Organizational Psychology, 77, 171-191.

van Knippenberg, D., \& van Schie, E. (2000). Foci and correlates of organizational identification. Journal of Occupational and Organizational Psychology, 73, 137-147. van Knippenberg, D., \& Sleebos, E. (2006). Organizational identification versus organizational commitment: Self-definition, social exchange, and job attitudes. Journal of Organizational Behavior, 27, 571-584.

van Steenbergen, E. F., Ellemers, N., Haslam, S. A., \& Urlings, F. (2008). There is nothing either 
good or bad but thinking makes it so: Informational support and cognitive appraisal of the work-family interface. Journal of Occupational and Organizational Psychology, 81, 349-367. van Zomeren, M., Leach, C. W., \& Spears, R. (2012). Protesters as “passionate economists” a dynamic dual pathway model of approach coping with collective disadvantage. Personality and Social Psychology Review, 16, 180-199.

Viswesvaran, C., Sanchez, J. I., \& Fisher, J. (1999). The role of social support in the process of work stress: A meta-analysis. Journal of Vocational Behavior, 54, 314-334.

Warr, P. B. (1990). Decision latitude, job demands, and employee well-being. Work \& Stress, 4, 285-294.

*Waszkowska, M., Andysz, A., \& Merecz, D. (2014). Person-organization fit as a mediator of the relationship between work environment and stress among social workers. Medycyna Pracy, 65, 219-228.

*Wegge, J., Schuh, S. C., \& van Dick, R. (2012). 'I feel bad', 'We feel good'? Emotions as a driver for personal and organizational identity and organizational identification as a resource for serving unfriendly customers. Stress \& Health, 28, 123-136.

*Wegge, J., van Dick, R., Fisher, G. K., Wecking, C., \& Moltzen, K. (2006). Work motivation, organisational identification, and well-being in call centre work. Work \& Stress, 20, 60-83.

*West, A. (2005). Organizational communication, bullying, and stress. Unpublished raw data, Psychology: College of Life and Environmental Science, University of Exeter, UK.

World Values Survey (2014). Retrieved 03 May 2016 from http://www.worldvaluessurvey.org/WVSDocumentationWV6.jsp

Zhang, S., Chen, G., Chen, X. P., Liu, D., \& Johnson, M. D. (2014). Relational versus collective identification within workgroups: Conceptualization, measurement development, and nomological network building. Journal of Management, 40, 1700-1731. 
*Zhang, R. Y., Liu, X. M., Wang, H. Z., \& Shen, L. (2011). Service climate and employee service performance: Exploring the moderating role of job stress and organizational identification. The Service Industries Journal, 31, 2355-2372. 
Table 1 Literatures (and Illustrative References) Related to Competing Hypotheses about the Nature of the Identification-Health Relationship

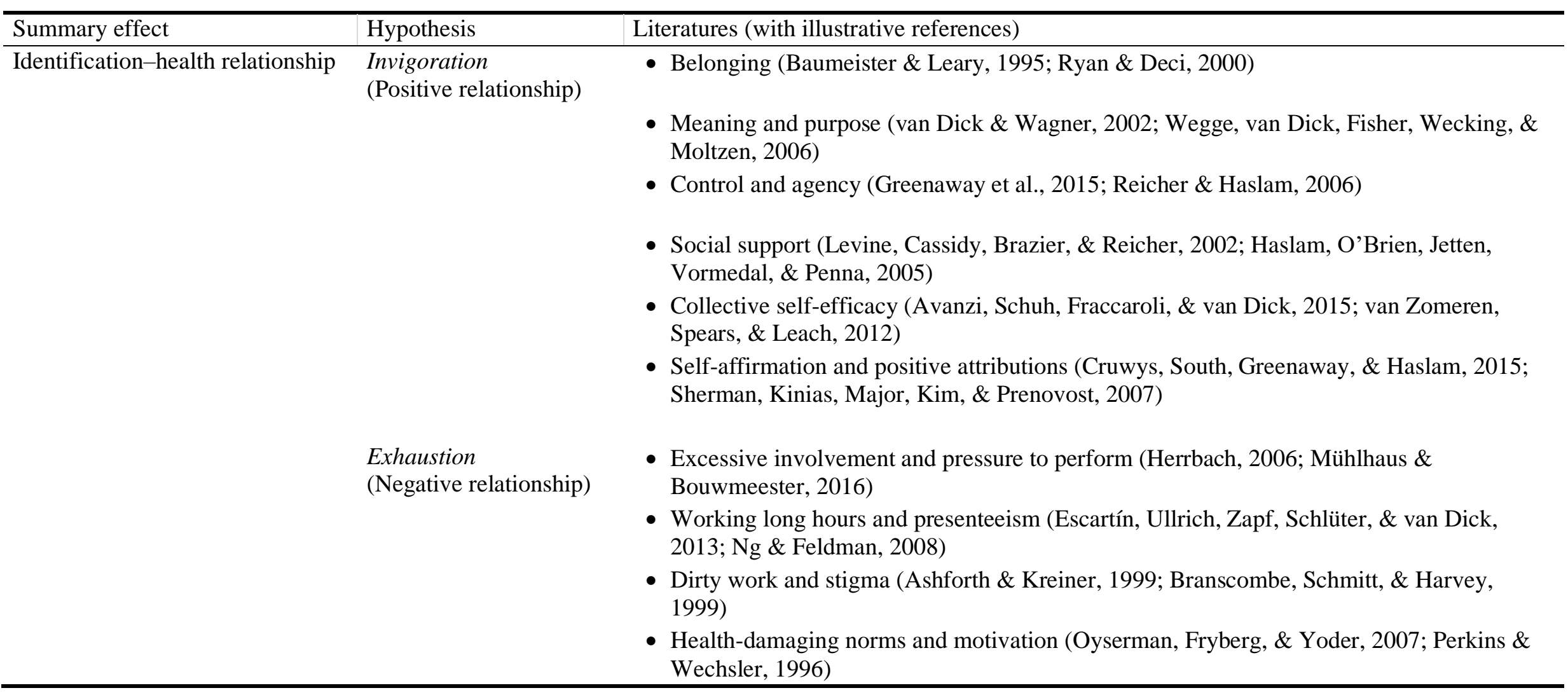


Table 2 Literatures (and Illustrative References) Related to Competing Hypotheses about the Impact of A-Priori Moderators on the Identification-Health Relationship

\begin{tabular}{|c|c|c|}
\hline Moderator & $\begin{array}{l}\text { Hypothesis } \\
\text { (stronger positive effects for) }\end{array}$ & Literatures (with illustrative references) \\
\hline \multirow[t]{3}{*}{ Identification focus } & Workgroup & $\begin{array}{l}\text { - Proximity and salience of group (Ashforth \& Johnson, 2001; van Knippenberg \& van } \\
\text { Schie, 2000) } \\
\text { - Familiarity with members and cohesion (Carron \& Spink, 1995; Moreland \& Levine, } \\
\text { 2001) }\end{array}$ \\
\hline & Organization & - Stability and continuity (Albert \& Whetten, 1985; Sani, Bowe, \& Herrera, 2008) \\
\hline & & - Public regard (Dutton, Dukerich, \& Harquail, 1994; Luhtanen \& Crocker, 1992) \\
\hline \multirow[t]{2}{*}{ Health valence } & Presence of well-being & - Positive human health (Ryff \& Singer, 1998; Thoits, 1994) \\
\hline & Absence of stress & - Stress buffering (Branscombe, Schmitt, \& Harvey, 1999; Thoits, 1986) \\
\hline \multirow[t]{3}{*}{ Health index } & Psychological health & $\begin{array}{l}\text { - Attitude-behavior compatibility in levels of analysis (Fishbein \& Aijzen, 1974; Riketta \& } \\
\text { van Dick, 2005) }\end{array}$ \\
\hline & & $\begin{array}{l}\text { - Connection with others jeopardizing physical health (Hopkins \& Reicher, 2016; Howell et } \\
\text { al., 2014) }\end{array}$ \\
\hline & Physical health & - \\
\hline \multirow[t]{3}{*}{ Sharedness in identification } & Shared & $\begin{array}{l}\text { - Solidarity (Drury, Cocking, \& Reicher, 2009; Reicher, Cassidy, Wolpert, Hopkins, \& } \\
\text { Levine, 2006) }\end{array}$ \\
\hline & & - Cohesion (Blanchard, Amiot, Perreault, Vallerand, \& Provencher, 2009; Griffith, 2002) \\
\hline & Non-shared & - Individual distinctiveness (Hornsey \& Jetten, 2004; Sheldon \& Bettencourt, 2002) \\
\hline
\end{tabular}


Table 3 Overview of Studies and Effect Sizes Concerning the Organizational Identification-Health Relationship (58 independent samples, 102 effect sizes, $N=19,799$ )

\begin{tabular}{|c|c|c|c|c|c|c|c|c|c|c|c|c|c|c|}
\hline Study & $\mathrm{CO}$ & Sample & $N$ & $r$ & $L L / U L$ & IF & IS & Val & Ind & SM & $\%$ 우 & Age & SS & $S D$ Id \\
\hline Ashforth \& Saks (1996) & $\mathrm{CA}$ & $\begin{array}{l}\text { Business graduates (workers in } \\
\text { various industries) }\end{array}$ & 294 & .08 & $-.03 / .19$ & $\mathrm{O}$ & $\mathrm{M}$ & $\mathrm{S}$ & Phys & $\mathrm{E} / \mathrm{L}$ & 59.90 & 23.50 & 68.40 & - \\
\hline $\begin{array}{l}\text { Avanzi, Fraccaroli, Sarchielli, } \\
\text { Ullrich, \& van Dick (2014) }\end{array}$ & IT & Workers in food industry & 195 & .16 & $.02 / .29$ & $\mathrm{O}$ & M & $\mathrm{S}$ & Psy & $\mathrm{C}-\mathrm{S}$ & 66.30 & 21.44 & 34.18 & 1.41 \\
\hline $\begin{array}{l}\text { Avanzi, Schuh, Fraccaroli, \& van } \\
\text { Dick (2014) }\end{array}$ & IT & Teachers & 192 & .24 & $.10 / .37$ & $\mathrm{O}$ & M & $\mathrm{S}$ & Psy & $\mathrm{C}-\mathrm{S}$ & 71.40 & 47.01 & 77.42 & - \\
\hline Effect size b & IT & Teachers & 192 & .15 & $.01 / .29$ & $\mathrm{O}$ & M & S & Psy & $\mathrm{C}-\mathrm{S}$ & 71.40 & 47.01 & 77.42 & - \\
\hline Effect size c & IT & Teachers & 192 & .14 & $.00 / .28$ & $\mathrm{O}$ & M & S & Psy & $\mathrm{C}-\mathrm{S}$ & 71.40 & 47.01 & 77.42 & - \\
\hline $\begin{array}{r}\text { Avanzi, van Dick, Fraccaroli, \& } \\
\text { Sarchielli (2012) Study } 1\end{array}$ & IT & Court employees & 195 & .08 & $-.06 / .22$ & $\mathrm{O}$ & M & WB & Psy & $\mathrm{C}-\mathrm{S}$ & 76.92 & 48.10 & 52.69 & - \\
\hline $\begin{array}{r}\text { Avanzi, van Dick, Fraccaroli, \& } \\
\text { Sarchielli (2012) Study } 2\end{array}$ & IT & Teachers & 140 & .08 & $-.09 / .24$ & $\mathrm{O}$ & M & WB & Psy & $\mathrm{C}-\mathrm{S}$ & 82.86 & 41.20 & 69.95 & - \\
\hline $\begin{array}{l}\text { Barbier, Dardenne, \& Hansez } \\
\text { (2013) }\end{array}$ & $\mathrm{BE}$ & Public administration workers & 473 & .33 & $.25 / .41$ & $\mathrm{O}$ & RO & S & Psy & $\mathrm{E} / \mathrm{L}$ & 56.03 & 48.71 & 52.30 & 1.32 \\
\hline Effect size $b$ & $\mathrm{BE}$ & Public administration workers & 473 & .13 & $.04 / .22$ & $\mathrm{O}$ & RO & $\mathrm{S}$ & Phys & $\mathrm{E} / \mathrm{L}$ & 56.03 & 48.71 & 52.30 & 1.32 \\
\hline Effect size c & $\mathrm{BE}$ & Public administration workers & 473 & .30 & $.22 / .38$ & $\mathrm{O}$ & RO & WB & Psy & $\mathrm{E} / \mathrm{L}$ & 56.03 & 48.71 & 52.30 & 1.32 \\
\hline Bedeian (2007) & US & Academics & 379 & .32 & $.23 / .41$ & $\mathrm{O}$ & M & $\mathrm{S}$ & Psy & $\mathrm{C}-\mathrm{S}$ & 36.88 & 45.00 & 80.62 & - \\
\hline $\begin{array}{l}\text { Bizumic, Reynolds, Turner, } \\
\text { Bromhead, \& Subasic (2009) }\end{array}$ & $\mathrm{AU}$ & Teachers & 113 & .16 & $-.03 / .33$ & $\mathrm{O}$ & RO & S & Psy & $\mathrm{C}-\mathrm{S}$ & 79.09 & 34.41 & 75.30 & - \\
\hline $\begin{array}{l}\text { Bjerregaard, Haslam, Morton, \& } \\
\text { Ryan (2014) }\end{array}$ & GB & Care staff & 1274 & .43 & $.38 / .47$ & $\mathrm{O}$ & $\mathrm{D}$ & $\mathrm{S}$ & Psy & $\mathrm{C}-\mathrm{S}$ & 89.68 & 42.57 & 43.09 & .99 \\
\hline Effect size $b$ & GB & Care staff & 1274 & .41 & $.36 / .45$ & $\mathrm{~W}$ & $\mathrm{D}$ & $\mathrm{S}$ & Psy & $\mathrm{C}-\mathrm{S}$ & 89.68 & 42.57 & 43.09 & - \\
\hline Christ (2004) & $\mathrm{DE}$ & Teachers in training internship & 93 & .08 & $-.13 / .28$ & $\mathrm{O}$ & $\mathrm{vD}$ & $S$ & Phys & $\mathrm{C}-\mathrm{S}$ & 73.12 & 27.56 & 65.87 & - \\
\hline $\begin{array}{l}\text { Cicero, Pierro, \& van Knippenberg } \\
\text { (2007) Study } 1\end{array}$ & IT & $\begin{array}{l}\text { Call center workers, nurses, } \\
\text { military officers }\end{array}$ & 329 & .29 & $.19 / .39$ & $\mathrm{~W}$ & M & S & Psy & $\mathrm{C}-\mathrm{S}$ & 50.15 & 35.26 & 43.72 & - \\
\hline Cicero, Pierro, \& van Knippenberg & IT & Workers in consumer electronics & 89 & .11 & $-.10 / .31$ & $\mathrm{~W}$ & M & $\mathrm{S}$ & Phys & $\mathrm{C}-\mathrm{S}$ & 62.92 & 38.65 & 42.80 & - \\
\hline
\end{tabular}




\section{(2007) Study $2 \quad$ company}

Das, Dharwadkar, \& Brandes (2008) IN Call center workers Effect size $b$

Fampri (2003)

Effect size $b$

Effect size c

Frisch, Häusser, van Dick, \& Mojzisch (2014)

Effect size $b$

Galang \& Jones (2014)

Grubba \& Ahlswede (2002)

Effect size b

Harris \& Cameron (2005)

Haslam, Jetten, \& Waghorn (2009)

Haslam, O’Brien, Jetten, Vormedal, \& Penna (2005) Study 2

Haslam \& Reicher (2006)

Effect size $b$

IN Call center workers

GR Workers electronics companies

GR Workers electronics companies

GR Workers electronics companies

DE Ad-hoc workgroup members

DE Ad-hoc workgroup members

GB Workers in various industries

DE Bank assistants

DE Bank assistants

CA Workers in food producing company

GB Theatre employees staff

GB Simulated guards and prisoners GB Simulated guards and prisoners

Häusser, Kattenstroth, van Dick, \& DE Ad-hoc workgroup members Mojzisch (2012)

Effect size $b$

Herrbach (2006)

Effect size $b$

Horton, McClelland, \& Griffin (2014) Study 1

Effect size $b$

Horton, McClelland, \& Griffin (2014) Study 2

Effect size b

Horton, McClelland, \& Griffin (2014) Study 3

GB Navy mid-level officers

GB Navy operational officers

FR Engineers

FR Engineers

GB Navy strategic officers

GB Navy strategic officers

GB Navy strategic officess
GB Bomb disposal workers and bar

$\begin{array}{cccccccccccc}132 & .19 & .02 / .35 & \mathrm{O} & \mathrm{M} & \mathrm{S} & \text { Psy } & \mathrm{C}-\mathrm{S} & 30.00 & 23.00 & 35.05 & 1.20 \\ 132 & .20 & .03 / .36 & \mathrm{O} & \mathrm{M} & \mathrm{S} & \text { Psy } & \mathrm{C}-\mathrm{S} & 30.00 & 23.00 & 35.05 & 1.20 \\ 68 & .20 & -.04 / .42 & \mathrm{O} & \mathrm{D} & \mathrm{S} & \text { Phys } & \mathrm{C}-\mathrm{S} & 54.41 & 30.00 & - & - \\ 68 & .38 & .16 / .57 & \mathrm{O} & \mathrm{D} & \mathrm{S} & \text { Psy } & \mathrm{C}-\mathrm{S} & 54.41 & 30.00 & - & - \\ 68 & .01 & -.23 / .25 & \mathrm{O} & \mathrm{D} & \mathrm{S} & \text { Psy } & \mathrm{C}-\mathrm{S} & 54.41 & 30.00 & - & - \\ 90 & .09 & -.12 / .29 & \mathrm{~W} & \mathrm{D} & \mathrm{S} & \text { Phys } & \mathrm{E} / \mathrm{L} & 54.44 & 22.00 & - & - \\ & & & & & & & & & & & \\ 90 & .01 & -.20 / .21 & \mathrm{~W} & \mathrm{D} & \mathrm{S} & \text { Psy } & \mathrm{E} / \mathrm{L} & 54.44 & 22.00 & - & - \\ 65 & -.41 & -.59 /-.19 & \mathrm{~W} & \mathrm{RO} & \mathrm{S} & \text { Psy } & \mathrm{C}-\mathrm{S} & 61.54 & 21.50 & - & - \\ 338 & .17 & .06 / .27 & \mathrm{O} & \mathrm{vD} & \mathrm{S} & \text { Phys } & \mathrm{C}-\mathrm{S} & 51.51 & 40.00 & 52.25 & - \\ 338 & .16 & .05 / .26 & \mathrm{~W} & \mathrm{vD} & \mathrm{S} & \text { Phys } & \mathrm{C}-\mathrm{S} & 51.51 & 40.00 & 52.25 & - \\ 60 & .14 & -.12 / .38 & \mathrm{~W} & \mathrm{D} & \mathrm{WB} & \text { Psy } & \mathrm{C}-\mathrm{S} & 40.00 & 39.37 & 28.38 & 1.47 \\ & & & & & & & & & & & \\ 30 & .47 & .17 / .69 & \mathrm{~W} & \mathrm{D} & \mathrm{S} & \text { Psy } & \mathrm{C}-\mathrm{S} & 40.00 & 20.80 & 58.16 & - \\ 40 & .63 & .40 / .79 & \mathrm{~W} & \mathrm{D} & \mathrm{S} & \text { Psy } & \mathrm{C}-\mathrm{S} & 25.00 & 25.58 & 47.55 & 1.25 \\ & & & & & & & & & & & \\ 15 & .43 & -.02 / .74 & \mathrm{~W} & \mathrm{D} & \mathrm{S} & \text { Phys } & \mathrm{E} / \mathrm{L} & 0.00 & 33.00 & 25.89 & - \\ 15 & .50 & .08 / .77 & \mathrm{~W} & \mathrm{D} & \mathrm{S} & \text { Psy } & \mathrm{E} / \mathrm{L} & 0.00 & 33.00 & 25.89 & - \\ 96 & .18 & -.01 / .37 & \mathrm{~W} & \mathrm{RO} & \mathrm{S} & \text { Phys } & \mathrm{E} / \mathrm{L} & 50.00 & 22.80 & - & - \\ & & & & & & & & & & & \\ 96 & .03 & -.17 / .23 & \mathrm{~W} & \mathrm{RO} & \mathrm{S} & \text { Psy } & \mathrm{E} / \mathrm{L} & 50.00 & 22.80 & - & - \\ 365 & .29 & .19 / .38 & \mathrm{O} & \mathrm{M} & \mathrm{WB} & \text { Psy } & \mathrm{C}-\mathrm{S} & 36.00 & 32.70 & 66.98 & - \\ 365 & -.22 & -.32 /-.12 & \mathrm{O} & \mathrm{M} & \mathrm{S} & \text { Psy } & \mathrm{C}-\mathrm{S} & 36.00 & 32.70 & 66.98 & - \\ 65 & .44 & .22 / .62 & \mathrm{O} & \mathrm{M} & \mathrm{WB} & \text { Psy } & \mathrm{C}-\mathrm{S} & 13.00 & 31.62 & 72.70 & 1.02 \\ & & & & & & & & & & & \\ 65 & .27 & .03 / .48 & \mathrm{~W} & \mathrm{M} & \mathrm{WB} & \text { Psy } & \mathrm{C}-\mathrm{S} & 13.00 & 31.62 & 72.70 & - \\ 381 & .20 & .10 / .29 & \mathrm{O} & \mathrm{M} & \mathrm{WB} & \text { Psy } & \mathrm{C}-\mathrm{S} & 8.00 & 33.71 & 72.70 & 1.35 \\ & & & & & & & & & & & \\ 381 & .20 & .10 / .29 & \mathrm{~W} & \mathrm{M} & \mathrm{WB} & \text { Psy } & \mathrm{C}-\mathrm{S} & 8.00 & 33.71 & 72.70 & - \\ 343 & .24 & .14 / .34 & \mathrm{O} & \mathrm{M} & \mathrm{WB} & \text { Psy } & \mathrm{C}-\mathrm{S} & 15.00 & 23.61 & 62.96 & 1.35\end{array}$

DE Ad-hoc workgroup members

$\begin{array}{lll}343 & .24 & .14 / .34\end{array}$ 


\begin{tabular}{|c|c|c|c|c|c|c|c|c|c|c|c|c|c|c|}
\hline Effect size $b$ & GB & Navy operational officers & 343 & .38 & $.29 / .47$ & $\mathrm{~W}$ & $\mathrm{M}$ & WB & Psy & $\mathrm{C}-\mathrm{S}$ & 15.00 & 23.61 & 62.96 & - \\
\hline Ishii (2012) & US & Japanese expatriates in US & 159 & .41 & $.27 / .53$ & $\mathrm{O}$ & RO & $\mathrm{S}$ & Psy & $\mathrm{C}-\mathrm{S}$ & 1.26 & 40.00 & - & - \\
\hline $\begin{array}{l}\text { Jimmieson, McKimmie, Hannam, \& } \\
\text { Gallagher (2010) }\end{array}$ & AU & Students in employment & 155 & .36 & $.21 / .49$ & $\mathrm{~W}$ & RO & WB & Psy & $\mathrm{C}-\mathrm{S}$ & 77.26 & 21.60 & - & - \\
\hline Effect size $b$ & $\mathrm{AU}$ & Students in employment & 155 & -.12 & $-.27 / .04$ & $\mathrm{~W}$ & RO & S & Psy & $\mathrm{C}-\mathrm{S}$ & 77.26 & 21.60 & - & - \\
\hline Knight \& Haslam (2010a) Study 1 & GB & Office workers & 288 & .26 & $.15 / .36$ & $\mathrm{O}$ & RO & WB & Phys & $\mathrm{C}-\mathrm{S}$ & 40.28 & 32.75 & 55.60 & - \\
\hline Effect size $b$ & GB & Office workers & 288 & .24 & $.13 / .35$ & $\mathrm{O}$ & RO & WB & Psy & $\mathrm{C}-\mathrm{S}$ & 40.28 & 32.75 & 55.60 & - \\
\hline Knight \& Haslam (2010a) Study 2 & GB & Office workers & 1643 & .20 & $.15 / .25$ & $\mathrm{O}$ & RO & WB & Phys & C-S & 66.22 & 28.84 & 55.60 & - \\
\hline Effect size $b$ & GB & Office workers & 1643 & .43 & $.39 / .47$ & $\mathrm{O}$ & RO & WB & Psy & $\mathrm{C}-\mathrm{S}$ & 66.22 & 28.84 & 55.60 & - \\
\hline Knight \& Haslam (2010b) Study 1 & GB & Workers in different industries & 112 & .15 & $-.04 / .33$ & $\mathrm{O}$ & $\mathrm{D}$ & WB & Phys & C-S & 64.29 & 37.55 & - & - \\
\hline Effect size $b$ & GB & Workers in different industries & 112 & .14 & $-.05 / .32$ & $\mathrm{O}$ & $\mathrm{D}$ & WB & Psy & $\mathrm{C}-\mathrm{S}$ & 64.29 & 37.55 & - & - \\
\hline Knight \& Haslam (2010b) Study 2 & GB & Office workers & 47 & .67 & $.47 / .80$ & $\mathrm{O}$ & $\mathrm{D}$ & WB & Phys & $\mathrm{C}-\mathrm{S}$ & 40.43 & 36.23 & 55.60 & - \\
\hline Effect size $b$ & GB & Office workers & 47 & .64 & $.43 / .78$ & $\mathrm{O}$ & $\mathrm{D}$ & WB & Psy & C-S & 40.43 & 36.23 & 55.60 & - \\
\hline Knowles \& Smith (2013) & GB & Office workers & 139 & .11 & $-.06 / .27$ & $\mathrm{~W}$ & RO & $\mathrm{S}$ & Psy & $\mathrm{C}-\mathrm{S}$ & 48.20 & 30.50 & 55.60 & - \\
\hline Kreiner \& Ashforth (2004) & US & University graduates & 330 & .43 & $.34 / .51$ & $\mathrm{O}$ & M & WB & Psy & $\mathrm{C}-\mathrm{S}$ & 56.06 & 43.60 & - & - \\
\hline Effect size $b$ & US & University graduates & 330 & .25 & $.15 / .35$ & $\mathrm{O}$ & M & $\mathrm{S}$ & Psy & $\mathrm{C}-\mathrm{S}$ & 56.06 & 43.60 & - & - \\
\hline Effect size c & US & University graduates & 330 & .15 & $.04 / .25$ & $\mathrm{O}$ & M & $S$ & Psy & C-S & 56.06 & 43.60 & - & - \\
\hline Matheson \& Cole (2004) & $\mathrm{CA}$ & Ad-hoc university group & 72 & .20 & $-.04 / .41$ & $\mathrm{O}$ & RO & $S$ & Phys & $\mathrm{C}-\mathrm{S}$ & 66.67 & 20.00 & - & - \\
\hline Effect size $b$ & CA & Ad-hoc university group & 72 & -.04 & $-.27 / .19$ & $\mathrm{O}$ & RO & S & Psy & C-S & 66.67 & 20.00 & - & - \\
\hline Effect size c & $\mathrm{CA}$ & Ad-hoc university group & 72 & .33 & $.11 / .52$ & $\mathrm{O}$ & RO & WB & Psy & $\mathrm{C}-\mathrm{S}$ & 66.67 & 20.00 & - & - \\
\hline Menzel (2007) & $\mathrm{DE}$ & Nurses & 220 & .11 & $-.02 / .24$ & $\mathrm{O}$ & RO & $\mathrm{S}$ & Phys & $\mathrm{C}-\mathrm{S}$ & 76.82 & 30.89 & 80.11 & 1.27 \\
\hline Effect size $b$ & $\mathrm{DE}$ & Nurses & 220 & .08 & $-.05 / .21$ & $\mathrm{~W}$ & RO & S & Phys & $\mathrm{C}-\mathrm{S}$ & 76.82 & 30.89 & 80.11 & - \\
\hline Merecz \& Andysz (2012) & PL & Workers in different industries & 576 & .18 & $.10 / .26$ & $\mathrm{O}$ & RO & WB & Psy & $\mathrm{C}-\mathrm{S}$ & 52.2 & 39.48 & - & - \\
\hline Mishra \& Bhatnagar (2010) & IN & Medical sales employees & 468 & .39 & $.31 / .46$ & $\mathrm{O}$ & M & $S$ & Psy & $\mathrm{C}-\mathrm{S}$ & 4.91 & 26.99 & 58.95 & - \\
\hline Effect size $b$ & IN & Medical sales employees & 468 & .23 & $.14 / .31$ & $\mathrm{O}$ & M & WB & Psy & $\mathrm{C}-\mathrm{S}$ & 4.91 & 26.99 & 58.95 & - \\
\hline $\begin{array}{l}\text { Effect size c (reported in Mishra, } \\
\text { 2013) }\end{array}$ & IN & Medical sales employees & 468 & .43 & $.35 / .50$ & $\mathrm{O}$ & M & $\mathrm{S}$ & Psy & $\mathrm{C}-\mathrm{S}$ & 5.00 & 26.99 & 58.95 & - \\
\hline $\begin{array}{c}\text { Nieuwenhuis, Knight, Postmes, \& } \\
\text { Haslam (2014) Study } 1\end{array}$ & GB & Consultants & 167 & .38 & $.24 / .50$ & $\mathrm{O}$ & $\mathrm{D}$ & WB & Psy & C-S & 40.74 & 29.88 & 70.38 & 1.24 \\
\hline Effect size $b$ & GB & Consultants & 167 & .44 & $.31 / .55$ & $\mathrm{~W}$ & $\mathrm{D}$ & WB & Psy & C-S & 40.74 & 29.88 & 70.38 & - \\
\hline Effect size c & GB & Consultants & 167 & .27 & $.12 / .41$ & $\mathrm{O}$ & $\mathrm{D}$ & $S$ & Psy & C-S & 40.74 & 29.88 & 70.38 & 1.24 \\
\hline Effect size $d$ & GB & Consultants & 167 & .27 & $.13 / .41$ & $\mathrm{~W}$ & $\mathrm{D}$ & S & Psy & C-S & 40.74 & 29.88 & 70.38 & - \\
\hline
\end{tabular}




\begin{tabular}{|c|c|c|c|c|c|c|c|c|c|c|c|c|c|c|}
\hline $\begin{array}{c}\text { Nieuwenhuis, Knight, Postmes, \& } \\
\text { Haslam (2014) Study } 2\end{array}$ & NL & Insurance service center workers & 128 & .11 & $-.06 / .28$ & $\mathrm{O}$ & $\mathrm{D}$ & WB & Psy & $\mathrm{C}-\mathrm{S}$ & 78.13 & 34.65 & 45.48 & 1.01 \\
\hline Effect size $b$ & NL & Insurance service center workers & 128 & .07 & $-.11 / .24$ & $\mathrm{~W}$ & $\mathrm{D}$ & WB & Psy & C-S & 78.13 & 34.65 & 45.48 & - \\
\hline Effect size c & NL & Insurance service center workers & 128 & .27 & $.10 / .43$ & $\mathrm{O}$ & $\mathrm{D}$ & WB & Psy & $\mathrm{C}-\mathrm{S}$ & 78.13 & 34.65 & 45.48 & 1.02 \\
\hline Effect size $d$ & NL & Insurance service center workers & 128 & .37 & $.21 / .51$ & $\mathrm{~W}$ & $\mathrm{D}$ & WB & Psy & C-S & 78.13 & 34.65 & 45.48 & - \\
\hline O’Brien \& Haslam (2004) & GB & Hospital staff & 1090 & .17 & $.11 / .23$ & $\mathrm{~W}$ & $\mathrm{D}$ & WB & Psy & C-S & 81.45 & 50.12 & 56.40 & - \\
\hline Effect size $b$ & GB & Hospital staff & 1090 & .25 & $.19 / .30$ & W & $\mathrm{D}$ & $S$ & Psy & C-S & 81.45 & 50.12 & 56.40 & - \\
\hline $\begin{array}{l}\text { Pisarski, Lawrence, Bohle, \& Brook } \\
\text { (2008) }\end{array}$ & AU & Nurses & 530 & .00 & $-.09 / .09$ & $\mathrm{~W}$ & M & WB & Psy & C-S & 92.64 & 35.00 & 36.60 & - \\
\hline Effect size $b$ & $\mathrm{AU}$ & Nurses & 530 & -.13 & $-.21 /-.05$ & $\mathrm{~W}$ & M & S & Phys & C-S & 92.64 & 35.00 & 36.60 & - \\
\hline Portaluri (2013) & $\mathrm{AU}$ & Teachers & 84 & -.14 & $-.34 / .08$ & $\mathrm{O}$ & RO & $\mathrm{S}$ & Psy & $\mathrm{E} / \mathrm{L}$ & 72.29 & 31.44 & 75.30 & - \\
\hline $\begin{array}{c}\text { Sani, Herrera, Wakefield, Boroch, \& } \\
\text { Gulyas (2012) }\end{array}$ & $\mathrm{EE}$ & Army members & 150 & .47 & $.33 / .59$ & $\mathrm{O}$ & RO & WB & Psy & C-S & 32.00 & 39.11 & 52.00 & .74 \\
\hline $\begin{array}{c}\text { Sani, Magrin, Scrignari, \& } \\
\text { McCollum (2010) }\end{array}$ & IT & Prison guards & 93 & .55 & $.39 / .68$ & $\mathrm{~W}$ & $\mathrm{D}$ & $S$ & Psy & C-S & 16.30 & 33.00 & 43.97 & 1.15 \\
\hline Effect size $b$ & IT & Prison guards & 93 & .47 & $.29 / 61$ & $\mathrm{~W}$ & $\mathrm{D}$ & S & Psy & C-S & 16.30 & 33.00 & 43.97 & 1.15 \\
\hline $\begin{array}{l}\text { Steffens, Yang, Jetten, Haslam, \& } \\
\text { Lipponen (2014) }\end{array}$ & $\mathrm{CN}$ & Engineering workers & 140 & .18 & $.01 / .34$ & $\mathrm{~W}$ & RO & WB & Psy & $\mathrm{E} / \mathrm{L}$ & 24.81 & 34.81 & 63.27 & - \\
\hline Effect size $b$ & $\mathrm{CN}$ & Engineering workers & 140 & .24 & $.08 / .39$ & $\mathrm{~W}$ & RO & WB & Psy & $\mathrm{E} / \mathrm{L}$ & 24.81 & 34.81 & 63.27 & - \\
\hline Effect size c & $\mathrm{CN}$ & Engineering workers & 140 & .28 & $.12 / .43$ & $\mathrm{~W}$ & RO & $\mathrm{S}$ & Psy & $\mathrm{E} / \mathrm{L}$ & 24.81 & 34.81 & 63.27 & - \\
\hline $\begin{array}{l}\text { Suh, Houston, Barney, \& Kwon } \\
\text { (2011) }\end{array}$ & US & Health care service workers & 3999 & .27 & $.24 / .30$ & $\mathrm{O}$ & M & $\mathrm{S}$ & Psy & C-S & 81.17 & 43.50 & 42.64 & 1.08 \\
\hline Topa \& Moriano (2013) & $\mathrm{ES}$ & Nurses & 388 & .27 & $.18 / .36$ & $\mathrm{~W}$ & M & S & Psy & C-S & 77.60 & 36.30 & 69.30 & - \\
\hline $\begin{array}{l}\text { van Dick, Stierle, Govaris, } \\
\text { Tissington, \& Kodakos } \\
\text { (2007) }\end{array}$ & $\begin{array}{l}\text { GR, } \\
\text { DE, } \\
\text { GB }\end{array}$ & Teachers & 367 & .08 & $-.02 / .18$ & $\mathrm{O}$ & RO & S & Phys & C-S & 44.78 & 42.73 & 73.77 & - \\
\hline Effect size $b$ & $\mathrm{DE}$ & Teachers & 367 & .05 & $-.05 / .15$ & $\mathrm{~W}$ & RO & $\mathrm{S}$ & Phys & C-S & 44.78 & 42.73 & 73.77 & - \\
\hline van Dick \& Wagner (2002) Study $1^{\mathrm{a}}$ & $\mathrm{DE}$ & Teachers & 201 & .27 & $.14 / .39$ & $\mathrm{O}$ & RO & $\mathrm{S}$ & Phys & C-S & 54.73 & 45.00 & 77.65 & - \\
\hline van Dick \& Wagner (2002) Study 2 & $\mathrm{DE}$ & Teachers & 283 & .28 & $.17 / .38$ & $\mathrm{~W}$ & RO & S & Phys & C-S & 54.77 & 46.00 & 77.64 & - \\
\hline $\begin{array}{l}\text { van Dick, Wagner, \& Lemmer } \\
\text { (2004) }\end{array}$ & $\mathrm{DE}$ & Hospital staff & 459 & .05 & $-.04 / .14$ & $\mathrm{O}$ & RO & $S$ & Psy & C-S & 38.00 & 41.74 & 84.51 & 1.82 \\
\hline van Dick, Wagner, Stellmacher, \& & $\mathrm{DE}$ & Teachers & 433 & .06 & $-.03 / .15$ & $\mathrm{O}$ & vD & $\mathrm{S}$ & Phys & $\mathrm{C}-\mathrm{S}$ & 61.43 & 46.08 & 77.94 & - \\
\hline
\end{tabular}




\begin{tabular}{|c|c|c|c|c|c|c|c|c|c|c|c|c|c|c|}
\hline Christ (2004) ${ }^{a}$ & & & & & & & & & & & & & & \\
\hline Effect size $b$ & $\mathrm{DE}$ & Teachers & 433 & .10 & $.01 / .19$ & $\mathrm{~W}$ & $\mathrm{vD}$ & $\mathrm{S}$ & Phys & C-S & 61.43 & 46.08 & 77.94 & - \\
\hline $\begin{array}{l}\text { Waszkowska, Andysz, \& Merecz } \\
\text { (2014) }\end{array}$ & PL & Social workers & 500 & .30 & $.21 / .37$ & $\mathrm{O}$ & $\mathrm{RO}$ & $\mathrm{S}$ & Psy & $\mathrm{C}-\mathrm{S}$ & 91.20 & 39.60 & 40.04 & - \\
\hline Wegge, Schuh, \& van Dick (2012) & $\mathrm{DE}$ & Call center workers & 96 & .07 & $-.13 / .27$ & $\mathrm{O}$ & $\mathrm{RO}$ & $\mathrm{S}$ & Phys & $\mathrm{C}-\mathrm{S}$ & 56.25 & 29.80 & 31.08 & - \\
\hline $\begin{array}{l}\text { Wegge, van Dick, Fisher, Wecking, } \\
\text { \& Moltzen (2006) }\end{array}$ & $\mathrm{DE}$ & Call center workers & 161 & .27 & $.12 / .41$ & $\mathrm{O}$ & $\mathrm{vD}$ & $\mathrm{S}$ & Phys & $\mathrm{C}-\mathrm{S}$ & 62.11 & 32.60 & 30.58 & - \\
\hline Effect size $b$ & $\mathrm{DE}$ & Call center workers & 161 & .40 & $.26 / .52$ & $\mathrm{O}$ & $\mathrm{vD}$ & $S$ & Psy & $\mathrm{C}-\mathrm{S}$ & 62.11 & 32.60 & 30.58 & - \\
\hline Effect size $c$ & $\mathrm{DE}$ & Call center workers & 161 & .28 & $.13 / .42$ & $\mathrm{O}$ & $\mathrm{vD}$ & $S$ & Psy & C-S & 62.11 & 32.60 & 30.58 & - \\
\hline Effect size $d$ & $\mathrm{DE}$ & Call center workers & 161 & .48 & $.35 / .59$ & $\mathrm{O}$ & vD & $S$ & Psy & C-S & 62.11 & 32.60 & 30.58 & - \\
\hline West (2005) & GB & Workers in different industries & 99 & .36 & $.18 / .52$ & $\mathrm{O}$ & RO & $\mathrm{S}$ & Psy & $\mathrm{C}-\mathrm{S}$ & 58.33 & 34.62 & - & - \\
\hline Zhang, Liu, Wang, \& Shen (2011) & $\mathrm{CN}$ & Bank assistants & 368 & -.18 & $-.28 /-.08$ & $\mathrm{O}$ & M & $S$ & Psy & C-S & 61.00 & 39.30 & 56.89 & - \\
\hline
\end{tabular}

Note. Total $N=19,799$ from 58 independent samples; Dashes indicate that particular indicator is not applicable in particular study; Study indicates an independent effect size; Effect size indicates a non-independent sample effect size; CO = country; CA = Canada; IT = Italy; BE = Belgium; AU = Australia; US = United States; GB = United Kingdom; DE = Germany; IN = India; GR = Greece; FR = France; PL = Poland; NL = Netherlands; EE = an Eastern European country (that authors of original research cannot disclose); $\mathrm{CN}=$ China; $\mathrm{ES}=$ Spain; $N$ indicates number of participants included in calculation of particular effect size; $r$ indicates sample size weighted corrected correlation between IV-DV; LL/UL indicate lower and upper 95\% limit of confidence interval; IF = identification focus; O = organization; W = workgroup; IS = identification scale; $\mathrm{M}=$ Mael \& Ashforth's (1992) scale; D = Doosje et al.'s (1995) scale; vD = van Dick et al.'s (2004) scale; RO = residual other scale; Val = health valence; $\mathrm{S}=$ absence of stress; $\mathrm{WB}=$ presence of well-being; Ind = health index; Psy = psychological health; Phys = physical health; $\mathrm{SM}=$ study methodology; CS = cross-sectional design; $\mathrm{E} / \mathrm{L}=$ experimental $/$ longitudinal design; $\% q=$ proportion of female participants in sample; Age = sample mean age; $\mathrm{SS}=$ social status of profession based on social stratification index CAMSIS; SD Id = standardized sample standard deviation in identification in samples in which all participants shared membership in the same entity. ${ }^{a}$ physical symptoms measure is not published in indicated article. 
Table 4 Interpretation of Results in Terms of Robustness of Evidence after Estimating and Correcting for Measurement and Publication Bias

\begin{tabular}{|c|c|c|}
\hline Key questions relating to robustness of evidence & Analysis & $\begin{array}{l}\text { Answer provided by statistical } \\
\text { significance (or other content) }\end{array}$ \\
\hline $\begin{array}{l}\text { Q1: Is the overall summary effect statistically significant when correcting for } \\
\text { measurement bias due to sampling error? }\end{array}$ & Random-effects model & Yes $(r=.21,95 \%$ CIs $[.17, .25])$ \\
\hline $\begin{array}{l}\text { Q2: How many independent studies with a correlation of zero would be needed } \\
\text { in file drawers to reduce summary effect to a small correlation of } r=.05 ?\end{array}$ & Fail-safe $N$ for effect size analysis & 217 studies \\
\hline $\begin{array}{l}\text { Q3: Is there evidence of publication bias as indicated by a statistically } \\
\text { significant linear relationship between effect size and standard error? }\end{array}$ & Funnel plot asymmetry test & No \\
\hline $\begin{array}{l}\text { Q4a: After computing effect sizes that are potentially missing due to } \\
\text { publication bias, is the unbiased summary effect statistically significant? }\end{array}$ & Trim and fill method & Yes \\
\hline $\begin{array}{l}\text { Q4b: Does unbiased summary effect estimate have the same substantive } \\
\text { implications than random-effects model estimate? }\end{array}$ & & Yes $(r=.18,95 \%$ CIs $[.14, .22])$ \\
\hline $\begin{array}{l}\text { Q5a: Is the overall summary effect in unpublished studies statistically } \\
\text { significant? }\end{array}$ & Subgroup analysis by publication status & Yes \\
\hline $\begin{array}{l}\text { Q5b: Does the summary effect based on published studies have larger } \\
\text { magnitude than the summary effect based on unpublished studies? }\end{array}$ & & No \\
\hline Q6a: Does the set of studies have evidential value? & $P$-curve analysis & Yes \\
\hline $\begin{array}{l}\text { Q6b: Is there evidence of publication bias due to } p \text {-hacking (or ambitious } p \text { - } \\
\text { hacking)? }\end{array}$ & & No \\
\hline $\begin{array}{l}\text { Q6c: Is there evidence that the existing evidential value is inadequate (due to } \\
\text { underpowered studies)? }\end{array}$ & & No \\
\hline $\begin{array}{l}\text { Q7a: Is there evidence of publication bias as indicated by a statistically } \\
\text { significant relationship between sample size and magnitude of effect size? }\end{array}$ & Cumulative meta-analysis & No \\
\hline $\begin{array}{l}\text { Q7b: Is there evidence of bias due to small-study effects (such that studies with } \\
\text { smaller samples have larger effect sizes)? }\end{array}$ & & No \\
\hline $\begin{array}{l}\text { Q7c: Does summary effect estimate based on large samples have the same } \\
\text { substantive implications as the random-effects model estimate? }\end{array}$ & & Yes $(r=.20,95 \%$ CIs $[.15, .25])$ \\
\hline
\end{tabular}


Table 5 Overview of Effect Sizes and Tests of Categorical Moderation Concerning the Organizational Identification-Health Relationship (58 independent samples, 102 effect sizes, $N=$ 19,799)

\begin{tabular}{|c|c|c|c|c|c|}
\hline Moderator & $r$ & $95 \% \mathrm{CIs}$ & $Z$ & $k$ & $Q$ \\
\hline \multicolumn{6}{|l|}{ Identification focus } \\
\hline Workgroup identification & .21 & $.14, .28$ & 5.90 & $16(26)$ & $202.90^{* *}$ \\
\hline Organizational identification & .21 & $.17, .26$ & 9.20 & $32(42)$ & $298.27^{* *}$ \\
\hline Between-group $Q$ & & & & & .14 \\
\hline \multicolumn{6}{|l|}{ Identification scale } \\
\hline Doosje et al. (1995) & .34 & $.25, .43$ & 6.98 & 12 & $67.78^{* *}$ \\
\hline Mael \& Ashforth (1992) & .18 & $.11, .24$ & 5.05 & 19 & $165.87^{* *}$ \\
\hline van Dick et al. (2004) & .17 & $.02, .32$ & 2.22 & 4 & $10.80^{* * *}$ \\
\hline Residual others & .18 & $.12, .25$ & 5.54 & 23 & $119.16^{* *}$ \\
\hline Between-group $Q$ & & & & & $9.80^{* *}$ \\
\hline \multicolumn{6}{|l|}{ Health Valence } \\
\hline Absence of Stress & .18 & $.12, .23$ & 6.43 & $35(45)$ & $443.96^{* *}$ \\
\hline Presence of Well-Being & .27 & $.22, .33$ & 9.37 & $13(23)$ & $129.05^{* *}$ \\
\hline Between-group $Q$ & & & & & $7.71^{* *}$ \\
\hline \multicolumn{6}{|l|}{ Health Index } \\
\hline Psychological Health & .23 & $.18, .28$ & 9.44 & $36(48)$ & $407.17^{* *}$ \\
\hline Physical Health & .16 & $.10, .22$ & 5.39 & $10(22)$ & $90.69^{* *}$ \\
\hline Between-group $Q$ & & & & & $4.87^{* *}$ \\
\hline \multicolumn{6}{|l|}{ Study methodology } \\
\hline Cross-sectional & .22 & $.18, .26$ & 10.04 & 50 & $377.65^{\text {** }}$ \\
\hline Longitudinal/experimental & .13 & $.01, .24$ & 2.11 & 8 & $19.03^{* *}$ \\
\hline Between-group $Q$ & & & & & 2.37 \\
\hline
\end{tabular}

Note. ${ }^{*} p<.10,{ }^{* *} p<.05 ; r$ indicates sample size weighted corrected correlation between organizational identification and health; 95\% CIs indicate lower and upper limits of 95\% confidence interval; The $k$ column indicates total number of samples including dependent and independent subgroups; Number in parenthesis indicates number of dependent samples; The $Q$ column indicates heterogeneity within each level of a variable $\left(Q_{\mathrm{w}}\right)$ and the test for heterogeneity between levels of a variable $\left(Q_{\mathrm{b}}\right)$. 
Study

\begin{tabular}{|c|c|c|c|}
\hline & \multicolumn{3}{|c|}{ Lower Upper } \\
\hline & Correlation & & limit \\
\hline Ashforth \& Saks (1996) & 0.08 & -0.03 & 0.19 \\
\hline Avanzi, Fraccaroli et al. (2014) & 0.16 & 0.02 & 0.29 \\
\hline Avanzi, Schuh et al. (2014) & 0.18 & 0.04 & 0.31 \\
\hline Avanzi, van Dick et al. (2012) Study 1 & 0.08 & -0.06 & 0.22 \\
\hline Avanzi, van Dick et al. (2012) Study 2 & 0.08 & -0.09 & 0.24 \\
\hline Barbier, Dardenne et al. (2013) & 0.26 & 0.17 & 0.34 \\
\hline Bedeian (2007) & 0.32 & 0.23 & 0.41 \\
\hline Bizumic, Reynolds et al. (2009) & 0.16 & -0.03 & 0.33 \\
\hline Bjerregaard, Haslam et al. (2014) & 0.42 & 0.37 & 0.46 \\
\hline Christ (2004) & 0.08 & -0.13 & 0.28 \\
\hline Cicero, Pierro et al. (2007) Study 1 & 0.29 & 0.19 & 0.39 \\
\hline Cicero, Pierro et al. (2007) Study 2 & 0.11 & -0.10 & 0.31 \\
\hline Das, Dharwadkar et al. (2008) & 0.20 & 0.02 & 0.35 \\
\hline Fampri (2003) & 0.20 & -0.04 & 0.42 \\
\hline Frisch et al. (2014) & 0.05 & -0.16 & 0.25 \\
\hline Galang \& Jones (2014) & -0.41 & -0.59 & -0.18 \\
\hline Grubba \& Ahlswede (2002) & 0.17 & 0.06 & 0.27 \\
\hline Harris \& Cameron (2005) & 0.14 & -0.12 & 0.38 \\
\hline Haslam \& Reicher (2006) & 0.47 & 0.03 & 0.75 \\
\hline Haslam, Jetten et al. (2009) & 0.47 & 0.17 & 0.69 \\
\hline Haslam, O'Brien et al. (2005) & 0.63 & 0.40 & 0.79 \\
\hline Hauesser, Kattenstroth et al. (2012) & 0.11 & -0.09 & 0.30 \\
\hline Herrbach (2006) & 0.04 & -0.07 & 0.14 \\
\hline Horton, McClelland et al. (2014) Study 1 & 0.36 & 0.12 & 0.55 \\
\hline Horton, McClelland et al. (2014) Study 2 & 0.20 & 0.10 & 0.29 \\
\hline Horton, McClelland et al. (2014) Study 3 & 0.31 & 0.21 & 0.40 \\
\hline Ishii (2012) & 0.41 & 0.27 & 0.53 \\
\hline Jimmieson, McKimmie et al. (2010) & 0.13 & -0.03 & 0.28 \\
\hline Knight \& Haslam (2010a) Study 1 & 0.25 & 0.14 & 0.36 \\
\hline Knight \& Haslam (2010a) Study 2 & 0.32 & 0.28 & 0.36 \\
\hline Knight \& Haslam (2010b) Study 1 & 0.15 & -0.04 & 0.32 \\
\hline Knight \& Haslam (2010b) Study 2 & 0.66 & 0.45 & 0.79 \\
\hline Knowles \& Smith (2013) & 0.11 & -0.06 & 0.27 \\
\hline Kreiner \& Ashforth (2004) & 0.28 & 0.18 & 0.38 \\
\hline Matheson \& Cole (2004) & 0.17 & -0.07 & 0.38 \\
\hline Menzel (2007) & 0.10 & -0.04 & 0.22 \\
\hline Merecz \& Andysz (2012) & 0.18 & 0.10 & 0.26 \\
\hline Mishra \& Bhatnagar (2010) & 0.35 & 0.27 & 0.43 \\
\hline Nieumenhuis, Knight et al. (2014) Study 1 & 0.34 & 0.20 & 0.47 \\
\hline Nieuwenhuis, Knight et al. (2014) Study 2 & 20.21 & 0.04 & 0.37 \\
\hline O'Brien \& Haslam (2003) & 0.21 & 0.15 & 0.27 \\
\hline Pisarski, Lawrence et al. (2008) & -0.07 & -0.15 & 0.02 \\
\hline Portaluri (2013) & -0.14 & -0.34 & 0.08 \\
\hline Sani, Herrera et al. (2012) Study 2 & 0.47 & 0.33 & 0.59 \\
\hline Sani, Magrin et al. (2010) & 0.51 & 0.34 & 0.65 \\
\hline Steffens, Yang et al. (2014) & 0.23 & 0.07 & 0.38 \\
\hline Suh, Houston et al. (2010) & 0.27 & 0.24 & 0.30 \\
\hline Topa \& Moriano (2013) & 0.27 & 0.18 & 0.36 \\
\hline van Dick \& Wagner (2002) Study 1 & 0.27 & 0.14 & 0.39 \\
\hline van Dick \& Wagner (2002) Study 2 & 0.28 & 0.17 & 0.38 \\
\hline van Dick, Stierle et al. (2007) & 0.07 & -0.04 & 0.17 \\
\hline van Dick, Wagner, Lemmer (2004) & 0.05 & -0.04 & 0.14 \\
\hline van Dick, Wagner, S., \& C. (2004) & 0.08 & -0.01 & 0.17 \\
\hline Waszkowska, Andysz et al. (2014) & 0.30 & 0.21 & 0.37 \\
\hline Wegge, Schuh et al. (2012) & 0.07 & -0.13 & 0.27 \\
\hline Wegge, van Dick et al. (2006) Study 2 & 0.36 & 0.22 & 0.49 \\
\hline West (2005) & 0.36 & 0.18 & 0.52 \\
\hline Zhang, Liu et al. (2011) & -0.18 & -0.28 & -0.08 \\
\hline & 0.21 & 0.17 & 0.25 \\
\hline
\end{tabular}

Plot of Correlations and $95 \% \mathrm{Cls}$

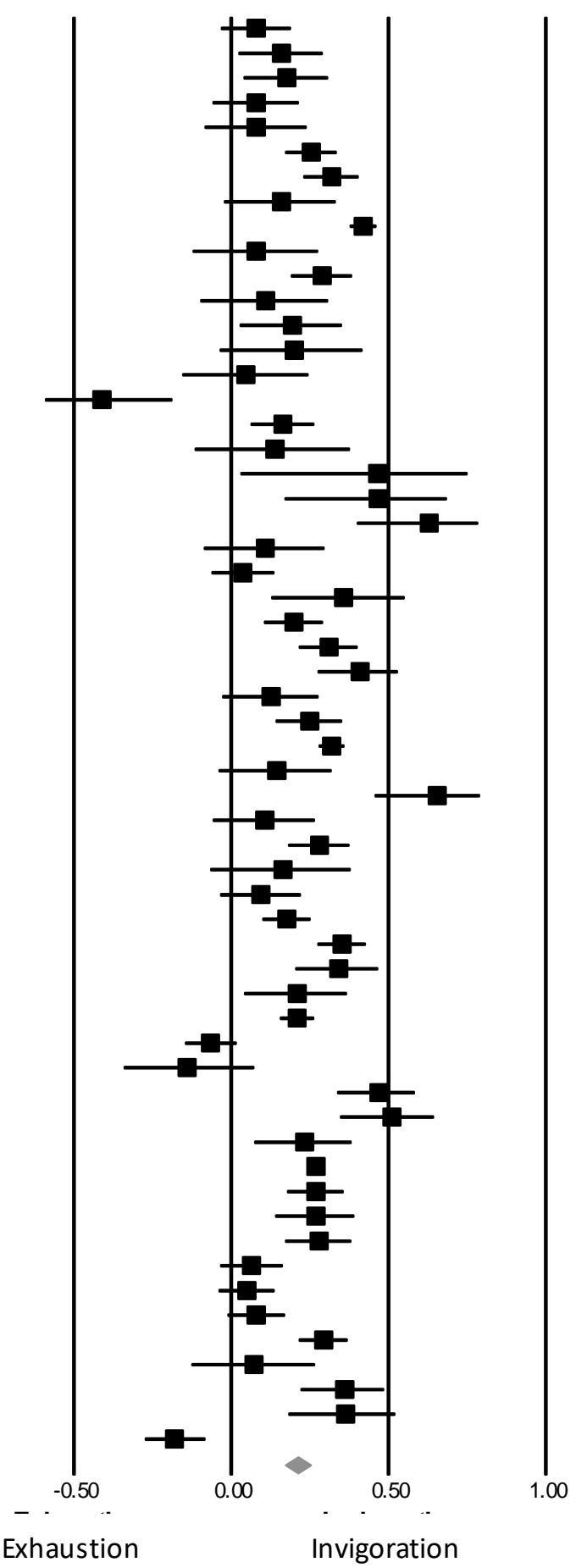

Figure 1 Forest Plot Displaying Effect Sizes, Confidence Intervals, and Weights in Estimation of Summary Effect for Independent Samples and Distribution of Effect Sizes around Summary Effect of Identification-Health Relationship 

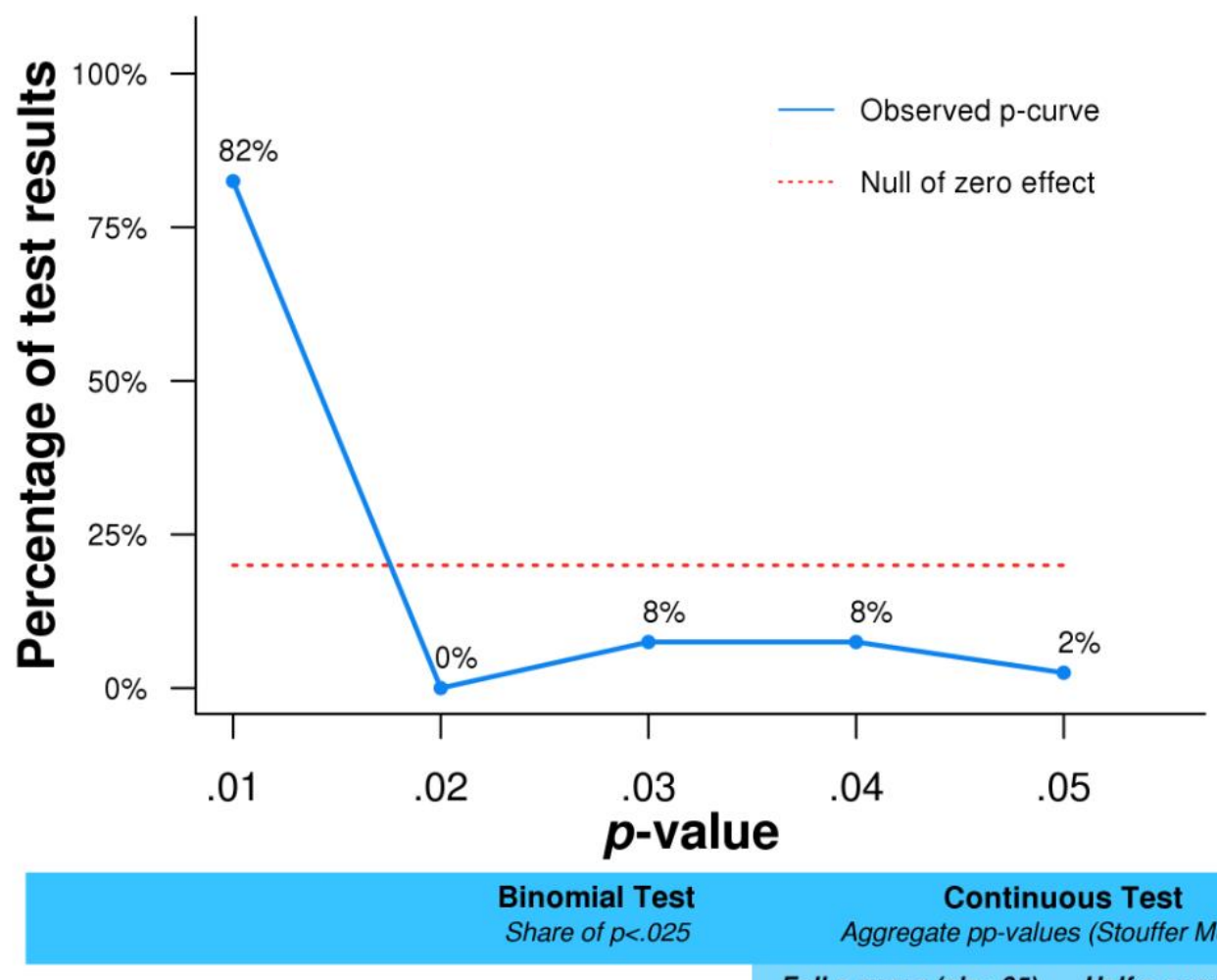

Binomial Test

Share of $p<.025$

\section{Continuous Test}

Aggregate pp-values (Stouffer Method)

Full $p$-curve ( $p$ 's<.05) Half $p$-curve $(p ' s<.025)$

1) Studies contain evidential value (Right-skew)

$p<.0001$

$Z=-21.24, p<.0001$

$Z=-22.09, p<.0001$

2) Evidential value, if any, is inadequate (Flatter than when power $=33 \%$ )

$p=.9876$

$Z=15.18, p>.9999$

$Z=19.23, p>.9999$

\section{Statistical Power}

Power of tests included in p-curve (Correcting for publication bias)

Estimate: $99 \%$

Confidence interval: $(99 \%, 99 \%)$

The observed $p$-curve includes 40 statistically significant $(p<.05)$ results, of which 34 are $p<.025$.

There were 17 additional results entered but excluded from $p$-curve because they were $p>05$.

Figure 2 P-Curve Displaying Observed P-Curve and Expected P-Curve if Effect Size was Zero. 
Study

Suh, Houston et al. (2010)

van Dick, Wagner, Lemmer (2004)

van Dick, Wagner, S., \& C. (2004)

Topa \& Moriano (2013)

Horton, McClelland et al. (2014) Study 2

IBedeian (2007)

Zhang, Liu et al. (2011)

van Dick, Stierle et al. (2007)

Herrbach (2006)

Horton, McClelland et al. (2014) Study 3

Grubba \& Ahlswede (2002)

Knight \& Haslam (2010a) Study 2

Kreiner \& Ashforth (2004)

Cicero, Pierro et al. (2007) Study 1

Ashforth \& Saks (1996)

Knight \& Haslam (2010a) Study 1

van Dick \& Wagner (2002) Study 2

Menzel (2007)

van Dick \& Wagner (2002) Study 1

Avanzi, Fraccaroli et al. (2014)

Avanzi, van Dick et al. (2012) Study 1

Avanzi, Schuh et al. (2014)

Bjerregaard, Haslam et al. (2014)

Nieuwenhuis, Knight et al. (2014) Study 1

Wegge, van Dick et al. (2006) Study 2

Ishii (2012)

Jimmieson, McKimmie et al. (2010)

Sani, Herrera et al. (2012) Study 2

Avanzi, van Dick et al. (2012) Study 2

Steffens, Yang et al. (2014)

Knowles \& Smith (2013)

Das, Dharwadkar et al. (2008)

Nieuwenhuis, Knight et al. (2014) Study 2

O'Brien \& Haslam (2003)

Bizumic, Reynolds et al. (2009)

Knight \& Haslam (2010b) Study 1

West (2005)

Hauesser, Kattenstroth et al. (2012)

Wegge, Schuh et al. (2012)

Christ (2004)

Sani, Magrin et al. (2010)

Frisch et al. (2014)

Cicero, Pierro et al. (2007) Study 2

Portaluri (2013)

Merecz \& Andysz (2012)

Matheson \& Cole (2004)

Fampri (2003)

Galang \& Jones (2014)

Horton, McClelland et al. (2014) Study 1

Harris \& Cameron (2005)

Knight \& Haslam (2010b) Study 2

Haslam, O'Brien et al. (2005)

Haslam, Jetten et al. (2009)

Haslam \& Reicher (2006)

Pisarski, Lawrence et al. (2008)

Waszkowska, Andysz et al. (2014)

Barbier, Dardenne et al. (2013)

Mishra \& Bhatnagar (2010)
Plot of Cumulative Correlations and 95\% Cls

Cumulative

Sample Size

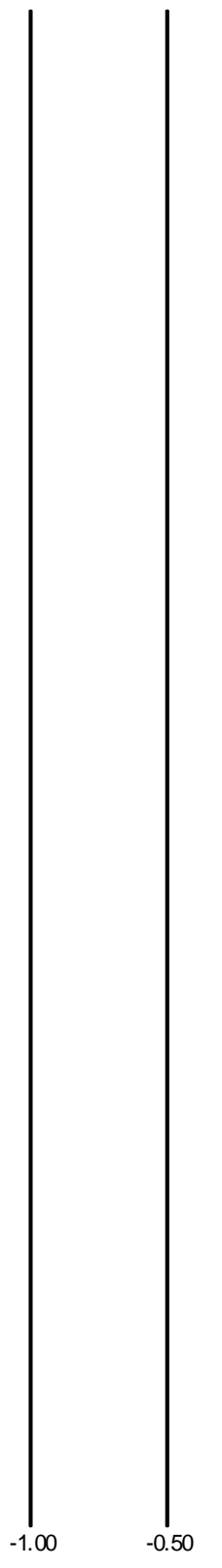

Exhaustion

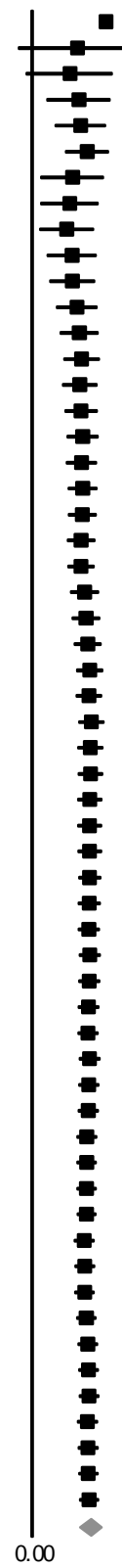

a

3999

4458
4891

4891
5279
5660

5660

6039
6407

6774

6774
7139
7482

7482

7820

9463
9793

10122

10416
10704

10987

11207

11408

11603

11798

11990

13264

13431

13592

13751

13906

14056

14196

14336

14475

14607

14735

15825

15938

16050

16149

16245

16341

16434

16527

16617

16706

16790

17366

17438

17506

17571

17636

17696

17743

17783

17813

17828

18358

18858

19331

19799

Figure 3 Cumulative Forest Plot Displaying Effect Sizes and Confidence Intervals with Studies Sorted by Sample Size (Smaller Studies are Cumulatively Added towards Bottom of Forest Plot) 